\title{
The Role of Surface Albedo Feedback in Climate
}

\author{
Alex Hall \\ University of California — Los Angeles \\ Department of Atmospheric Sciences \\ Box 951565 \\ Los Angeles, CA 90095 USA
}

contact information:

Alex Hall

Tel: (310) 206-5253

e-mail: alexhall@atmos.ucla.edu

submitted to Journal of Climate 


\begin{abstract}
A coarse resolution coupled ocean-atmosphere simulation where surface albedo feedback is suppressed by prescribing surface albedo is compared to one where snow and sea ice anomalies are allowed to affect surface albedo. Canonical $\mathrm{CO}_{2}$-doubling experiments were performed with both models to assess the impact of this feedback on equilibrium response to external forcing: It accounts for about half the high-latitude response to the forcing. Both models were also run for 1000 years without forcing to assess the impact of surface albedo feedback on internal variability. Surprisingly little internal variability can be attributed to this feedback, except in the northern hemisphere continents during spring and in the sea ice zone of the southern hemisphere at all times of year. At these locations and during these seasons, it accounts for at most $20 \%$ of the variability. The reason for this relatively weak signal is that other damping processes dilute the impact of surface albedo feedback.

When snow albedo feedback in northern hemisphere continents is isolated from these other damping processes, it has a similar strength in the $\mathrm{CO}_{2}$ doubling and internal variability contexts; a given temperature anomaly in these regions produces approximately the same change in snow depth and surface albedo whether it was externally-forced or internallygenerated. This suggests the presence of internal variability in the observed record is not a barrier to extracting information about snow albedo feedback's contribution to equilibrium climate sensitivity. This is demonstrated in principle in a 'scenario run', where estimates of past, present, and future changes in greenhouse gases and sulfate aerosols are imposed on the model with surface albedo feedback. This simulation contains a mix of internal variations and externally-forced anomalies similar to the observed record. The snow albedo feedback to the scenario run's climate anomalies agrees very well with the snow albedo feedback in the $\mathrm{CO}_{2}$ doubling context. Moreover, the portion of the scenario run corresponding to the present-day satellite record is long enough to capture this feedback, suggesting this record could be used to estimate snow albedo feedback's contribution to equilibrium climate sensitivity.
\end{abstract}




\section{Introduction}

When subjected to an increase in greenhouse gases, most coupled ocean-atmosphere models exhibit more warming in mid to high latitudes than the tropics (e.g. Cubasch et al, 2001). The enhanced extratropical sensitivity may be partly due to surface albedo feedback (SAF), a mechanism first brought to the attention of the climate community by Budyko (1969) and Sellers (1969). In the warmer climate, snow and ice retreat, exposing land and ocean surfaces that are much less reflective of solar radiation. The additional absorbed solar radiation results in more warming, especially in the region of the snow and ice reduction.

One goal of this study is to quantify the impact of SAF on the equilibrium climate response to external forcing. This is done by comparing the quasi-equilibrium climate change resulting from $\mathrm{CO}_{2}$-doubling in coarse resolution coupled ocean-atmosphere models with and without SAF. This allows the contribution of SAF to climate sensitivity to be isolated from other processes, such as changes in sea ice thickness, which can be important in modulating the seasonal distribution of warming in areas covered by sea ice (Manabe and Stouffer, 1980; Robock, 1983). SAF is suppressed by prescribing surface albedo to seasonally-varying, climatological-mean values in the portion of the model that calculates solar radiation. Snow and ice anomalies may occur in this simulation, but they do not affect solar radiation. This method of 'turning off' SAF is similar to that of Hall and Manabe $(1999,2000 a)$, who disabled water vapor feedback in the same coupled ocean-atmosphere model and compared the climate change in the resulting simulation to one where water vapor feedback was fully operative.

If radiative feedbacks have a significant effect on equilibrium climate sensitivity, it is plausible they also have an impact on internally-generated climate variability. Hall and Manabe (1999, 2000b) also examined this issue, comparing the internal variability in a simulation where water vapor feedback was artificially suppressed to one with water vapor feedback intact. They 
concluded that fully one-third of simulated global-mean temperature variability is attributable to water vapor feedback. Is a similarly large proportion of internal climate variability attributable to SAF? A second goal of this study is to quantify the impact of SAF on internal climate variations by comparing unperturbed coupled ocean-atmosphere model simulations with and without SAF. This is the first time the impact of SAF on climate sensitivity and internal climate variability has been isolated in a coupled ocean-atmosphere model.

How radiative feedbacks such as water vapor feedback and SAF contribute to both the sensitivity and variability of the climate system are interesting and fundamental climate dynamics problems in their own right. Understanding the behavior of radiative feedbacks in both sensitivity and variability contexts is also crucial to the interpretation of climate feedbacks in the observed record. If it were possible to extract information about the real climate's equilibrium climate sensitivity from the observed record, this would lead to more accurate predictions of the climate's future evolution under the influence of external forcing. But the observed record contains a tangled mix of externally-forced and internally-generated climate anomalies; if a particular feedback behaves differently in the sensitivity and variability contexts, then it is not straightforward to extract information about equilibrium climate sensitivity from the observed record. On the other hand, if a particular feedback behaves in a similar way in these two contexts, then the presence of internal variability in the observed record may not be a barrier to extracting information about its effect on equilibrium climate sensitivity.

If the behavior of the feedback in the sensitivity and variability contexts is different, then it becomes necessary to consider whether the observed record is dominated by the statistics of externally-forced climate change or internal climate variability. It may be possible to extract information from the observed record about equilibrium sensitivity if the external forcing is large enough and the climate system is in thermodynamic equilibrium with it. In this case, the sig- 
natures of equilibrium sensitivity would simply overwhelm those of internal variability. On the other hand, if the real climate were not in equilibrium with the external forcing, an assessment of the equilibrium sensitivity based on the observed record would be complicated even if the real record contained only externally-forced climate variations and no internal variability. The behavior of a feedback in the transient response to the forcing might differ from its equilibrium response behavior.

Using standard feedback analysis techniques relating top-of-the-atmosphere radiative fluxes to surface air temperature (SAT) anomalies, it is demonstrated in this study that the SAF due to sea ice behaves very differently in the sensitivity and variability contexts. Moreover, sea ice albedo feedback predominates in the southern hemisphere $(\mathrm{SH})$ extratropical oceans, a part of the world where the response time scale of the climate to external forcing is probably on the order of decades due to the large effective heat capacity of the Southern Ocean (Manabe et al., 1991). These two problems pose significant barriers to the extraction of information about the contribution of sea ice albedo feedback to equilibrium climate sensitivity from the observed record. In this study it is also demonstrated the SAF due to snow behaves very similarly in the sensitivity and variability contexts. In addition, snow albedo feedback predominates in the northern hemisphere $(\mathrm{NH})$ extratropical land areas, a part of the world where the response time scale to external forcing is probably relatively short. The similarity in the behavior of snow albedo feedback in the sensitivity and variability contexts, along with with the high degree of equilibrium of $\mathrm{NH}$ continents with external forcing, together raise the possibility that the contribution of snow albedo feedback to equilibrium climate sensitivity is easily detected in the observed record.

Armed with this knowledge of the behavior of SAF, a 'scenario run' is also analyzed in this study. In this experiment, estimates of past, present, and future changes in greenhouse gases and sulfate aerosols from 1765 to 2094 are imposed on the model with SAF. This experiment 
contains a mix of internal variability and externally-forced climate change similar to that of the observed record. The scenario run is also likely to be in equilibrium with the external forcing imposed on it to a similar degree as the real climate. This experiment can be analyzed to assess how practical it would be to extract information from the observed record about SAF's behavior in the equilibrium climate change context, in particular whether the barriers to extracting information about sea ice albedo feedback will ever be surmountable, and also whether extracting information about snow albedo feedback is possible at the present time.

The internal variability experiments, the scenario run, and the $\mathrm{CO}_{2}$-doubling experiments, each performed with the same modeling framework, together comprise a unique suite of experiments designed to investigate the behavior of SAF in internal variability, transient climate change, and equilibrium climate sensitivity.

This study is presented as follows: A description of the coupled ocean-atmosphere model is given in section 2, followed by a discussion of the method used to suppress SAF in section 3. The effect of SAF on equilibrium climate sensitivity is discussed in section 4 . Then, in section 5 , the behavior of SAF in the variability and sensitivity contexts is compared. Finally, the possibility of obtaining information about SAF from the observed record is evaluated in the scenario run (section 6). A summary and concluding remarks are found in section 7.

\section{Model Description}

\subsection{General}

A brief description of the coupled model is given here. For more details, see Manabe et al. (1991). It consists of general circulation models (GCM) of the atmosphere and oceans, and a land surface model. It is global in scope, with geography as realistic as possible given its res- 
olution. The atmospheric component has nine vertical finite difference levels. The horizontal distributions of predicted variables are represented by spherical harmonics (15 associated Legendre functions for each of 15 Fourier components) and by grid-point values (Gordon and Stern 1982), which have a spacing of approximately $4.5^{\circ}$ latitude by $7.5^{\circ}$ longitude. A simple land surface model is used to compute surface fluxes of heat and water (Manabe 1969). Insolation varies seasonally, but not diurnally. Cloud cover is predicted based on relative humidity.

The finite-difference oceanic component, with a horizontal resolution of approximately $4.5^{\circ}$ latitude by $3.75^{\circ}$ longitude and 12 vertical levels, uses the Modular Ocean Model (MOM) code described in Pacanowski et al. (1991). This particular version of MOM is based, in turn, on a model described by Bryan and Lewis (1979). In addition to horizontal and vertical background sub-grid scale mixing, the model has isopycnal mixing as discussed by Redi (1982) and Tziperman and Bryan (1993). Convection occurs whenever the vertical stratification becomes unstable. Sea ice is predicted using a free drift model developed by Bryan (1969). It computes sea ice thickness from a thermodynamic heat balance and the advection of ice by ocean currents. The atmospheric and oceanic components of the model interact with each other once each day through exchange of heat, water and momentum. Because of the model's coarse resolution, it is necessary to impose flux adjustments of heat and water at the air-sea interface to maintain the model in a realistic mean state. Though these adjustments do not eliminate the model's shortcomings (Marotzke and Stone, 1995), they do not change from one year to the next and are independent of the sea surface temperature and salinity anomalies that develop during the integration.

\subsection{Surface Albedo Parameterization}

Since the subject of this article is SAF, a description of the model's surface albedo parameterization is given. Even if it were incorporated into perfect models of the atmosphere, ocean, and 
land, this parameterization would not produce perfectly realistic surface albedo variations as it does not include every possible effect of variations in surface properties on local surface albedo. Its aim instead is to simulate in an easily interpretable way the average relative brightnesses of open ocean, bare land, snow, sea ice, and ice sheets.

Over ice-free ocean regions, surface albedo is prescribed as a function of latitude. Over ice-covered ocean regions, surface albedo is parameterized as a function of ice thickness and surface temperature. Fig 1a illustrates this dependence for a typical ocean point with an an ice-free albedo of $10 \%$. Surface albedo increases with increasing ice thickness and decreasing surface temperature from the ice-free value to a maximum value of $80 \%$ for ice thicknesses greater than $1 \mathrm{~m}$ and temperatures lower than $-10^{\circ} \mathrm{C}$. Between 0 and $1 \mathrm{~m}$, the dependence on ice thickness has a parabolic form. The temperature dependence in the -10 to $0^{\circ} \mathrm{C}$ range is linear and is intended to reproduce the albedo effects of meltwater on top of the ice as well as the fact that colder ice is more likely to be covered with highly reflective snow than warmer ice (Grenfell and Perovich, 1984; Allison et al., 1993; Barry, 1996; Massom et al., 2001). Above $0^{\circ} \mathrm{C}$, there is no temperature dependence.

Over land, the influence of snow on surface albedo is treated in a similar way to the influence of ice in the ocean. Over snow-free areas, surface albedo is prescribed according to vegetation cover and land surface type. (The impact of vegetation anomalies on surface albedo is not included in the model.) Over snow-covered land regions, surface albedo is parameterized as a function of snow depth and surface temperature. Fig $1 \mathrm{~b}$ illustrates this dependence for a typical land point with a snow-free albedo of $20 \%$. Surface albedo increases with increasing snow depth and decreasing surface temperature from the snow-free value to a maximum value of $60 \%$ for snow depths greater than $2 \mathrm{~cm}$ (water equivalent) and temperatures lower than $-10^{\circ} \mathrm{C}$. Between 0 and $2 \mathrm{~cm}$, the dependence on snow depth has a parabolic form. The linear dependence on 
temperature in the -10 to $0^{\circ} \mathrm{C}$ range is intended to take into account the fact that wet snow, more common at higher temperatures, typically has a lower albedo than completely frozen snow (Wiscombe and Warren, 1980). Above $0^{\circ} \mathrm{C}$, there is no temperature dependence. The model does not contain any glacial dynamics. Instead, the Greenland and Antarctic ice sheets are prescribed. However, fresh snow is allowed to accumulate on the ice sheets, and surface albedo is allowed to vary with snow depth and surface temperature in a manner similar to other land points, albeit with a much higher snow-free value (55\%) and a much higher maximum value (80\%) for snow depths greater than $2 \mathrm{~cm}$ and temperatures below $-10^{\circ} \mathrm{C}$ (fig 1c). This is meant to take into account the albedo effects of fresh snow and melting on top of the glacier, such as those observed by Stroeve et al. (1997).

Comparing figs $1 \mathrm{a}$ and $\mathrm{b}$, simulated sea ice is generally more reflective of sunshine than snow on land. For example, below $-10^{\circ} \mathrm{C}$, thick sea ice, presumably snow-covered at these low temperatures, has an albedo of $80 \%$. Deep snow on land in the same temperature range has a smaller albedo-60\%. Though deep fresh snow on a flat unvegetated land surface has a similar albedo to snow-covered ice, the maximum albedo of snow-covered land regions is deliberately set to a lower value because relatively dark vegetation sometimes rises above the top of the snow pack in the real climate, particularly in heavily forested regions, reducing typical surface albedos of snow-covered land areas (see e.g. Robock, 1980).

\section{Experimental Design}

As noted in section 1, this model was integrated in two configurations to test the effects of SAF. In both configurations, snow cover and sea ice are variable. However, in the configuration without SAF, surface albedos at all grid points are fixed to their climatological mean, seasonally-varying value in the shortwave portion of the radiative transfer subroutine. This configuration will be 
referred to hereafter as the FA configuration (for fixed albedo). In the configuration with SAF, on the other hand, the surface albedo values based on predicted snow cover and sea ice are passed to the shortwave subroutine. This configuration will be referred to hereafter as the VA configuration (for variable albedo). The surface albedo field used in the FA model was calculated in the following way: First, integrating only the atmospheric component of the coupled model, and using seasonally-varying, climatological sea surface temperatures and sea ice as a lower boundary condition, the daily mean values of the entire surface albedo field were saved away for fifty years. Then the values corresponding to any given day of the annual cycle were averaged over all fifty years of the integration, providing a mean albedo field for every day of the year. These values were supplied to the coupled model's shortwave radiative transfer subroutine as the coupled integration proceeded through each day of the year. Since only surface albedo was fixed in the FA model, the effects of variable cloudiness and water vapor on planetary albedo are included in both model configurations. This aspect of albedo feedback is therefore not a subject of this study. Moreover, since no vegetation model is included, it is only the change in the surface albedo due to variations in snow and ice that is addressed.

To elucidate the effects of SAF on internal climate variability, each model configuration was integrated for 1000 years with $\mathrm{CO}_{2}$ fixed at 360 ppm, near the present day global-mean value. Although the flux adjustment technique described in section 2.1 minimizes climate drift, small multi-century trends in most climate variables remain in both experiments. To prevent their contaminating the analysis of internal climate variability they must be removed. One difficulty with standard detrending techniques is that these trends are not always linear. To circumvent this issue, all data were subject to a $50 \mathrm{yr}$ high pass filter prior to analysis. This eliminates all multicentury trends associated with climate drift, whether or not they are linear. This also has the added advantage of focusing attention on time scales of variability for which the model time se- 
ries offers a high degree of statistical significance. For example, after applying a 101 point 50 $\mathrm{yr}$ high pass filter to $1000 \mathrm{yrs}$ of annual-mean data, there remain 18 realizations of $50 \mathrm{yr}$ time scale climate variations (after accounting for data loss due to filtering at the ends of the time series). This is enough to provide reasonably stable statistics. For shorter time scales, there are of course even more realizations, and hence even more reliable statistics.

Using the same initial conditions as the internal variability experiments, $\mathrm{CO}_{2}$-doubling experiments were performed to assess the impact of SAF on equilibrium climate sensitivity. Integrating using both model configurations, $\mathrm{CO}_{2}$ was increased at a rate of $1 \%$ per year until its concentration doubled, around year 70 . Thereafter, it was fixed at the doubled value (720 ppm) for the remainder of the 500 year long experiments. The climate in such an experiment would likely continue to change at a slow rate for several centuries in response to the new $\mathrm{CO}_{2}$ value if the integrations were continued beyond year 500 . However, enough of the climate change has occurred toward the end of these integrations that we may consider the climate at this stage to be broadly representative of the equilibrium response to the increase in $\mathrm{CO}_{2}$. To assess this response, the climate variables averaged over the 5th century of these experiments were compared to the climate variables averaged over the 5 th century of the internal variability experiments, where $\mathrm{CO}_{2}$ was held constant at $360 \mathrm{ppm}$.

An additional experiment was performed, referred to as the 'scenario run'. Here estimates of past, present, and future sulfate aerosol and greenhouse gas concentrations were imposed on the VA model. This forcing history, which begins in 1765 and ends in 2094, corresponds to the IPCC's IS92a emissions scenario (1992). The technique used to force the model is identical to that of Haywood et al. (1997) and Mitchell et al. (1995). Briefly, the radiative forcing associated with the increases in greenhouse gas concentrations were converted to increases in equivalent $\mathrm{CO}_{2}$, while the direct radiative forcing of the sulfate aerosols was simulated by increasing the 
surface albedo. The initial conditions for the scenario run were taken from the end of the 1000yr-long VA internal variability experiment, when the simulated climate exhibits little drift. Trends in the scenario run time series are therefore attributable to external forcing. Since $\mathrm{CO}_{2}$ was fixed to $360 \mathrm{ppm}$ in the VA internal variability experiment, $\mathrm{CO}_{2}$ concentrations started out at $360 \mathrm{ppm}$ in the scenario run. The greenhouse gas radiative forcing of the IS92a emissions scenario was then simulated by raising subsequent $\mathrm{CO}_{2}$ levels above $360 \mathrm{ppm}$. Thus while the initial conditions of the scenario run correspond more to the present-day climate than the climate in 1794, the climate perturbation induced by the external forcing corresponds to the climate perturbation during the 1794-2094 period. Surface albedo data used to analyze this experiment includes only the effect of snow and ice variations and does not include any of the anomalies imposed to mimick the effect of sulfate aerosols.

\section{Equilibrium Climate Sensitivity}

\subsection{SAF}

The left column of fig 2 shows the quasi-equilibrium SAT increase that takes place as a result of $\mathrm{CO}_{2}$-doubling in the VA experiment. The geographical and seasonal distribution of the warming is a familiar one (see e.g. Manabe and Stouffer, 1980). There is significantly more warming in high latitudes during all seasons, with the largest polar amplification seen during fall and winter in both hemispheres. The high latitude warming is smallest during summertime in both hemispheres, with spring lying between these two extremes. SAF plays a significant role in generating the

poleward amplification pattern seen in the left column of fig 2 . This is apparent by examining the SAT increase that takes place as a result of $\mathrm{CO}_{2}$ doubling in the FA experiment (fig 2, right column). When SAF is suppressed, the warming in high latitudes is drastically reduced, with little 
poleward amplification seen during summer and spring in either hemisphere.

The effect of SAF may be quantified by examining the VA/FA ratio of the $\mathrm{CO}_{2}$-induced warming (dashed lines, fig 3). There is about twice as much warming near the $\mathrm{SH}$ sea ice zone in the VA experiment during all seasons. The SAF amplification decreases poleward of the ice margin to about $50 \%$ over Antarctica. It also decreases equatorward to values of about $20 \%$ in the tropics. In the $\mathrm{NH}$ during winter, spring, and fall, the amplification rises gradually from $20 \%$ at about $30^{\circ} \mathrm{N}$ to more than $70 \%$ at the pole. During $\mathrm{NH}$ summer, an amplification of about $60 \%$ is more concentrated over the Arctic.

Consistent with a strong positive SAF, the climate in the VA experiment with doubled $\mathrm{CO}_{2}$ has markedly less snow and ice, increasing the net incoming insolation in the mid to high latitudes of both hemispheres (fig 4). In the $\mathrm{NH}$, the reduction in snow over land rather than the reduction in sea ice contributes most to the change in incoming shortwave during winter and fall. During spring, the reduction in snow and ice contribute about equally, while in summer, a reduction in Arctic sea ice is responsible for most of the increase in shortwave radiation, snow cover being negligible at this time of year except over the Greenland ice sheet. In the $\mathrm{SH}$, the increase in shortwave radiation can be traced almost exclusively to a reduction in sea ice, with a slight change in the albedo of the Antarctic ice sheet making a small contribution during $\mathrm{SH}$ summer.

With the exception of SON, the peak warming ratios of fig 3 are larger in the $\mathrm{SH}$ than the $\mathrm{NH}$. This is probably due partly to the fact that snow albedo feedback plays a large role in the overall NH SAF, whereas the SH SAF is overwhelmingly dominated by sea ice reductions. Since the albedo contrast between sea ice and open ocean is greater than the the albedo contrast between snow and bare land (fig 1), the effect of SAF is somewhat larger in the SH.

It is clear from figs 3 and 4 that the effects of SAF are largest in the areas where the surface albedo changes as a result of $\mathrm{CO}_{2}$ doubling in the VA experiment. The sea ice reduction is 
responsible for the nearly all the change in incoming insolation in the $\mathrm{SH}$, and the largest ratios in the $\mathrm{SH}$ are seen in the sea ice zone. Similarly, in the $\mathrm{NH}$, the large effect of the decrease in snow cover during SON, DJF, and MAM is seen in large warming ratios in the mid to high latitude areas where snow is found during these seasons. When snow disappears in $\mathrm{NH}$ summer, the largest ratios become confined to the Arctic, where a large decrease in sea ice albedo takes place.

Also significant is the extent to which large effects of SAF are seen in fig 3 outside the areas where surface albedo changes. There is about $50 \%$ more warming in Antarctica in all seasons, in spite of the fact that the albedo of the Antarctic ice sheet hardly changes even in summer (fig 4); more than $2^{\circ} \mathrm{C}$ of the annual-mean SAT increase simulated over Antarctica in the VA model is attributable to SAF. There is also about $20 \%$ more warming in the deep tropics during all seasons in the VA model, in spite of the total absence of any $\mathrm{CO}_{2}$-induced change in surface albedo in the VA model in this region. This corresponds to a warming difference of about $0.5^{\circ} \mathrm{C}$. The warming attributable to SAF in areas outside the regions directly affected by

it must occur because atmospheric and possibly oceanic motion diffuse the heat anomaly away from the sea ice and snow zone. A detailed analysis of this effect is beyond the scope of this paper. However, evidence of it can also be seen in other modeling studies. Ingram et al. (1989) noticed the tropics warm less in climate change modeling experiments where sea ice extent is prescribed, and Broccoli (2000) quantified the simulated impact of the NH ice sheets of the last glacial maximum on tropical SSTs.

\subsection{Ice thickness feedback}

The seasonal distribution of the $\mathrm{CO}_{2}$-induced warming in areas covered by sea ice in the VA model (fig 2, left column) does not match the seasonal distribution of the increased solar radiation 
at the surface (fig 4). The Arctic warming is largest in $\mathrm{NH}$ fall and winter, when sunshine is weakest, and the $\mathrm{CO}_{2}$-induced change in incoming solar radiation due to sea ice reduction is minuscule. Similarly, the warming in the Southern Ocean is largest in $\mathrm{SH}$ fall and winter, also when the least increase in incoming solar radiation due to sea ice albedo feedback occurs.

Analyzing an atmospheric model similar to the present one coupled to mixed layer model of the ocean, Manabe and Stouffer (1980) highlighted the importance of the $\mathrm{CO}_{2}$-induced change in sea ice thickness in modulating the seasonal distribution of climate change. Robock (1983), analyzing an energy balance model, also highlighted the importance of this 'ice thickness feedback'. The $\mathrm{CO}_{2}$ increase, the humidity increase, and the decrease in surface albedo all act to increase the downward radiative fluxes at the surface throughout the year. However, during ice melt season (spring and summer), almost all of this additional energy goes into melting more ice, with a relatively small effect on surface temperature. The loss of sea ice in spring and summer then leads to significantly thinner ice throughout the ice pack when it grows again in fall and winter. This facilitates more sensible heat transfer from the warm ocean to the frigid atmosphere during fall and winter, generating a large increase in SAT. The sensible heat increase is very effective in generating warming near the surface during fall and winter because the polar atmosphere is so stratified during these seasons, so that all of the effects of the sensible heat flux change are concentrated in the lowest layers of the atmosphere.

Because the FA climate change experiment lacks SAF, much of the seasonal variation in the quasi-equilibrium warming seen in this experiment can be attributed to the ice thickness feedback alone. Comparing the left and right columns of fig 2 , the seasonal variations in the positions of the warming maxima in areas covered by sea ice are very similar in the FA model. Thus the conclusion of Robock (1983), based on an energy-balance model, that ice thickness feedback is the main determinant of the seasonal distribution of warming in sea-ice covered regions even 
when SAF is present, is supported by this study using full-blown general circulation models of the atmosphere and ocean.

In winter and fall of both hemispheres, there is a large degree of polar amplification of the climate change signal in the experiment without SAF, with nearly three times as much warming in high latitudes than the tropics. However, on an annual-mean basis, polar amplification in the FA model is much smaller, being hardly detectable in the $\mathrm{SH}$, and somewhat apparent in the $\mathrm{NH}$ (fig 5). In the VA model, on the other hand, the annual-mean polar amplification is dramatic, with nearly twice as much warming in the $\mathrm{SH}$ high latitudes as in the tropics, and more than twice as much warming in the $\mathrm{NH}$ high latitudes. This indicates that to first-order, SAF is the reason more warming generally occurs at high latitudes, with ice thickness feedback being the mechanism determining how this additional warming is distributed seasonally. This is reasonable, since SAF actually increases the solar energy absorbed in high latitudes, while ice thickness feedback is a non-radiative feedback that merely redistributes energy within the system.

\section{Comparing SAF in sensitivity and variability contexts}

This section is divided into two parts. In section 5.1, the amplifying effect of SAF on SAT anomalies is compared in the $\mathrm{CO}_{2}$-doubling and internal variability contexts. This allows for an examination of how other mechanisms affecting the damping of SAT anomalies, including non-radiative processes such as ice thickness feedback and mixing of heat within the atmosphere, can alter the impact of SAF in these two contexts. Then, in section 5.2, the behavior of the SAF in $\mathrm{CO}_{2}$-doubling and internal variability contexts is examined in isolation from other damping mechanisms. This allows similarities and differences between the behavior of SAF in the sensitivity and variability contexts obscured by the influence of other damping mechanisms to emerge. 


\subsection{Direct effect of SAF on SAT anomalies}

The solid lines in figure 3 show the VA/FA ratio of zonal-mean standard deviation of seasonalmean local SAT in the internal variability experiments for all four seasons. This metric provides a quantitative assessment of the impact of SAF on the typical magnitudes of SAT anomalies at the smallest scale resolved by the model. If the ratios are much larger than one, SAF significantly amplifies local internal variability. In the $\mathrm{NH}, \mathrm{SAF}$ seems to have little effect on internal variability, with the ratios being close to one for all seasons except spring. Approximately $20 \%$ more springtime SAT variability occurs in the extratropics in the experiment with SAF. This amplification can be traced entirely to continents. In the $\mathrm{SH}$, the effect of SAF is visible during all seasons and is especially pronounced near the sea ice margin, where there is typically a $30-40 \%$ enhance-

ment of local SAT variability. Comparing the solid and dashed lines of fig 3 , the relatively weak effect of SAF on local internal variability contrasts starkly with the large effect of SAF on climate change at all latitudes during all seasons. Also significant is the large influence of SAF on the externally-forced SAT anomaly in the Arctic. This NH sea ice albedo feedback is largely absent in the internal variability case. SAF only amplifies local internally-generated NH SAT variability significantly through snow albedo feedback in the spring.

The effect of SAF on local internal variability is so much smaller than its effect on externallyforced climate change partly because of the ice thickness feedback discussed in section 4.2 . It has been noted before that the apparent impact of a positive feedback mechanism is amplified by the presence of another positive feedback (Hall and Manabe, 1999; Robock, 1983). The presence of this positive ice thickness feedback enhances the apparent impact of SAF in the $\mathrm{CO}_{2}$ doubling context. On the other hand, the ice thickness feedback is weak in the internal variability case because internally-generated SAT variations are not as large as the warming due to a doubling of $\mathrm{CO}_{2}$ and are associated with correspondingly smaller changes in ice thickness. 
The sensible heat flux through the ice is proportional to the reciprocal of the ice thickness, so that small perturbations in ice thickness result in proportionately smaller perturbations to sensible heat flux than the sensible heat flux increase caused by a large reduction in ice thickness. There is therefore little enhancement of the apparent impact of SAF on internal variability due to the ice thickness feedback.

\begin{tabular}{|l|l|l|l|l|}
\hline & DJF & MAM & JJA & SON \\
\hline NH & 0.12 & 0.17 & 0.19 & 0.15 \\
\hline SH & 0.23 & 0.24 & 0.28 & 0.26 \\
\hline
\end{tabular}

Table 1: Top row: Typical values of the correlations between seasonal-mean SAT averaged over the $\mathrm{NH}$ poleward of $30^{\circ} \mathrm{N}$ and local seasonal-mean SAT in the VA internal variability experiment. The values in the table were calculated by generating a correlation at every grid point and then averaging these correlations over the extratropics poleward of $30^{\circ} \mathrm{N}$. Bottom row: As in the top row, except for the SH poleward of $30^{\circ} \mathrm{S}$.

Another important reason for the larger effect of SAF on climate change is related to the differing geographical structures of internally-generated and externally-forced climate variations. While the externally-forced SAT anomaly has the same sign everywhere, internal SAT variations are not nearly so geographically coherent. In the NH extratropics, for example, the typical correlations between local internal SAT variations and SAT variations averaged over the extratropics are quite small for all seasons (table 1), never rising above 0.25 . The typical correlations between local SAT variations and SAT variations averaged over the extratropics poleward of $30^{\circ} \mathrm{S}$ are similarly small in the SH. This implies that local SAT variations in the regions of both hemispheres potentially most affected by SAF typically have a spatial scale much smaller than the two extratropical zones poleward of $30^{\circ} \mathrm{N}$ and S. These relatively small-scale anomalies are therefore damped by horizontal heat exchange with surrounding regions as well as radiative fluxes at the 
top of the atmosphere. This dilutes the effects of radiative damping processes such as SAF on local internal SAT variations, and reduces the impact of eliminating SAF in the FA experiment. When the smaller-scale internal SAT anomalies most affected by horizontal damping are eliminated by averaging SAT over the entire extratropics, the effect of SAF increases substantially (compare the left two bars in each panel of fig 6). This is particularly true in the NH during MAM, and in the $\mathrm{SH}$ during all seasons. This confirms that horizontal damping is partially responsible for the small impact of SAF on local internal SAT variability seen in fig 3.

The effect of SAF on internal extratropical-mean variations is still not as large as its effect on the $\mathrm{CO}_{2}$-induced SAT anomaly during any season (compare the right two bars in each panel of fig 6), despite the fact that horizontal damping effects are reduced by averaging the internal SAT variations over the extratropics. This difference occurs partly because of the enhancement of the apparent impact of SAF on the externally-forced anomaly due to the ice thickness feedback, particularly in the $\mathrm{SH}$, where variability in the cryosphere is overwhelmingly dominated by changes in sea ice. Of course horizontal damping of extratropical-mean SAT anomalies is still possible through heat exchange with the tropics across $30^{\circ} \mathrm{N}$ and S. This effect is likely to be more significant in the case of internal variability than externally-forced climate change, as internal tropical temperature anomalies are not necessarily correlated with their extratropical counterparts, whereas the $\mathrm{CO}_{2}$-induced warming occurs at all latitudes. This is another reason for the difference between the right two bars of each panel of fig 6 .

\subsection{Strength of SAF in isolation from other damping mechanisms}

While the final impact of SAF on internally-generated SAT anomalies is attenuated because of a weak ice thickness feedback and because it is diluted by horizontal damping, it is possible that the radiative effects of SAF are similar in the internal variability and $\mathrm{CO}_{2}$ doubling contexts, even 
if the final impact of the feedback on SAT anomalies is different. To examine the strength of SAF in isolation from other processes, the classical climate sensitivity framework relating changes in climate variables to changes in outgoing longwave and incoming shortwave radiation is used (see e.g. Cess and Potter, 1988). According to this framework, the strength of radiative feedbacks can be quantified in terms of a climate sensitivity parameter $\lambda$ :

$$
\lambda=\frac{d F}{d T_{s}}-\frac{d Q}{d T_{s}}
$$

where $F$ is the outgoing longwave radiation, $T_{s}$ is the SAT, and $Q$ is the net incoming shortwave radiation. The subject of this paper being SAF, we focus here on the SAF contribution to $d Q / d T_{s}$ :

$$
\left(\frac{\partial Q}{\partial T_{s}}\right)_{S A F}=\frac{\partial Q}{\partial \alpha_{s}} \cdot \frac{d \alpha_{s}}{d T_{s}}
$$

where $\left(\partial Q / \partial T_{s}\right)_{S A F}$ is the variation in net incoming shortwave radiation with SAT due to surface albedo changes and $\alpha_{s}$ is the surface albedo. The partial derivative $\partial Q / \partial \alpha_{s}$ is simply the variation in net incoming solar radiation with surface albedo. This is determined by cloud and incoming solar radiation fields. Of course, cloud will vary in association with internally-generated and externally-forced climate anomalies, so that $\partial Q / \partial \alpha_{s}$ may not be exactly constant. How longterm variations in cloudiness may indirectly modulate SAF is an interesting and complex topic for future research, but is beyond the scope of this paper. Instead, the focus is on the process most central to SAF itself: the relationship between surface albedo and SAT (i.e. the $d \alpha_{s} / d T_{s}$ term of eq 2). In the internal variability case, this relationship may be diagnosed by regressing surface albedo onto SAT in the VA model (fig 7, grey bars). In the sensitivity case, this relationship may be diagnosed by dividing the VA model's $\mathrm{CO}_{2}$-induced change in surface albedo by the $\mathrm{CO}_{2}$-induced change in SAT (fig 7, black bars). It is customary in this type of feedback analysis to analyze global-mean quantities. However, $\mathrm{NH}$ and $\mathrm{SH}$ extratropical-means are analyzed first in this study to reveal potentially meaningful differences between the behavior of SAF in the two 
hemispheres.

In the $\mathrm{SH}$, systematically smaller changes in surface albedo occur on a per ${ }^{\circ} \mathrm{C}$ basis in the $\mathrm{CO}_{2}$-doubling case during all seasons. This is due to the ice thickness feedback, which increases the SAT anomaly associated with a given change in surface albedo stemming from a sea ice reduction. As noted above, this feedback is strong for the $\mathrm{CO}_{2}$-induced anomaly, but weak for internal variations. Unfortunately the ice thickness feedback also contaminates the relationship between surface albedo and SAT in the climate change context. Since SAF in the $\mathrm{SH}$ is overwhelmingly controlled by changes in sea ice (fig 4), this makes it very difficult to quantify SH SAF in the climate change context by examining a time series dominated by internal variability.

At times of year when sea ice rather than snow variations are the main factor behind SAF in the $\mathrm{NH}$, SAF also behaves very differently in the sensitivity and variability contexts, though for different reasons than in the SH. In the sensitivity context, large reductions in Arctic sea ice thickness are the most important factor behind SAF in the NH during JJA, when snow practically disappears as a result of the $\mathrm{CO}_{2}$ increase (fig 4). On the other hand, internal Arctic SAT variations are relatively small during JJA and to the extent that they do affect underlying ice thickness, they do not do so enough to cause substantial changes in the surface albedo. An examination of the standard deviation of JJA surface albedo in the VA internal variability experiment (not shown) reveals that most of the very small amount of surface albedo variability in the $\mathrm{NH}$ occurring at this time of year takes place over the Greenland ice sheet. Here the melting snow on top of the glacier causes surface albedo excursions depending on its depth and temperature (see bottom panel, fig 1). Since Greenland accounts for a very small portion of the total area of the NH extratropics, this explains why minuscule surface albedo changes are associated with $a 1^{\circ} \mathrm{C}$ internal SAT anomaly (fig 7 , top panel), while a relatively large surface albedo change per ${ }^{\circ} \mathrm{C}$ warming 
occurs in the $\mathrm{CO}_{2}$ doubling context.

Why do NH summertime internal SAT anomalies lead to such small sea ice albedo anomalies in the Arctic, while their SH counterparts are associated with large sea ice albedo excursions? (Compare for example, the internal variability surface albedo-SAT relationships during $\mathrm{NH}$ and SH summer, i.e. the JJA grey bar in the top panel of fig 7 to the DJF grey bar in the bottom panel of the figure.) NH sea ice is largely hemmed in by the boundaries of the Arctic basin, while the boundary of $\mathrm{SH}$ ice is not constrained by land at any longitude. The thickness of the ice at the $\mathrm{SH}$ ice margin is therefore much thinner than the ice at the northern edges of the North American and Eurasian continents. So internal SAT anomalies in the SH can much more easily affect the areal extent of the SH ice pack and hence the overall albedo of the SH extratropics by melting or forming small amounts of ice at the $\mathrm{SH}$ ice margin. In the $\mathrm{NH}$, free variations in ice extent at all longitudes are not possible until the climate warms enough to retract the ice margin from the Arctic basin perimeter. This does not occur in the unperturbed climate, even during summertime. In SON, DJF, and MAM, the internal sea ice albedo variability also makes a small contribution to the overall surface albedo variability, most of which is produced by variations in snow amount. The reason again is that the ice pack boundary in the $\mathrm{NH}$ is constrained at most longitudes to the boundaries of the Arctic basin. This accounts for the minuscule impact of sea ice albedo feedback on internal Arctic SAT variability during all seasons (fig 3).

While the SAF resulting from sea ice clearly behaves differently in the sensitivity and variability contexts in both hemispheres, SAF resulting from snow on land behaves similarly. Suggestions of this can be seen in the surface albedo-SAT relationship when snow on land is the main contributor to SAF (SON, DJF, and MAM in the $\mathrm{NH}$, according to fig 4). During these seasons, much closer agreement between the internal variability and $\mathrm{CO}_{2}$ doubling cases is seen in the surface albedo-SAT relationships. However, this cannot be considered definitive evidence be- 
cause some SAF due to sea ice occurs during these seasons in the $\mathrm{CO}_{2}$-doubling context (fig 4). Moreover, though the area of the Arctic is small compared to the entire extratropics, most of the Arctic SAT increase seen in fall, winter, and spring in the $\mathrm{VA} \mathrm{CO}_{2}$ doubling experiment (fig 2, left column) is a result of thinner ice during these seasons, which in turn results from strong surface albedo feedback and melting during summer, as discussed in section 4.2. The SAT data used to calculate the black bars in the top panel of fig 7 is therefore somewhat contaminated by ice thickness feedback effects even during SON, DJF, and MAM, when SAF itself due to sea ice is relatively weak (fig 4).

To test the idea that SAF due to snow might behave in the same way in internal variability and external forcing contexts, the surface albedo-SAT relationship is examined in $\mathrm{NH}$ snowcovered regions only (fig 8 , top panel). The $\mathrm{CO}_{2}$-doubling case is discussed first (black bars). A $1^{\circ} \mathrm{C}$ warming anomaly over snow covered areas is associated with the smallest surface albedo reduction during fall and winter, a somewhat larger reduction during spring, and the largest reduction during summer.

The seasonal dependence of the surface albedo-SAT relationship is similar to the seasonal dependence of the snow depth-SAT relationship (fig 8, bottom panel). The same $1^{\circ} \mathrm{C}$ warming is associated with the smallest snow depth reduction during fall and winter, a somewhat larger snow depth reduction during spring, and the largest snow depth reduction during summer. The seasonal dependence of the snow depth-SAT relationship is likely traceable to the fact that accumulation is the dominant factor affecting the size of the snow pack during fall and winter, while melting is the dominant factor affecting its size during spring. In winter and fall, the warming reduces snow mostly because the line between rain and snow moves poleward, whereas in spring, warm temperatures are associated with less snow mostly because more of the snow pack melts. A $1^{\circ} \mathrm{C}$ warm SAT anomaly during spring produces more snow melt than a $1^{\circ} \mathrm{C}$ warm 
SAT anomaly during fall and winter reduces snow accumulation because in spring temperatures are high enough that the increased melting affects much of the snow pack. In fall and winter, on the other hand, the poleward retreat of the rain/snow line only reduces snow accumulation at the snow margin. The only snow found in the $\mathrm{NH}$ during summer in the model is on the Greenland ice sheet. The values shown in fig 8 for JJA therefore pertain exclusively to the dynamics of the summertime snow budget over Greenland. The warming has a very large effect on snow depth and surface albedo here because the mean summertime SATs hover very close to freezing all over the ice sheet, so that the warming causes both snow melt and a reduction in the precipitation falling as snow rather than rain.

The relationship in $\mathrm{NH}$ snow-covered areas between internally-generated SAT anomalies and anomalies of surface albedo and snow depth (fig 8, grey bars) shows precisely the same seasonal dependence as the relationships in the context of external forcing (black bars), suggesting identical mechanisms are at work in determining the SAT, surface albedo, and snow relationships in the two cases. Moreover, the magnitudes of the surface albedo and snow depth anomalies associated with a $1^{\circ} \mathrm{C}$ SAT anomaly are in reasonably close agreement for all seasons whether the anomaly is externally-forced or internally-generated. Identical analyses to that shown in fig 8 but for the Eurasian and North American snow pack separately (not shown) give very similar results. This indicates that the simulated snow albedo feedback operates in much the same way in the internal variability and $\mathrm{CO}_{2}$-doubling contexts.

\section{The scenario run}

In this section, the scenario run is analyzed to assess how practical it would be to extract information from the observed record about SAF's behavior in the equilibrium climate change context, in particular whether the barriers to extracting information about sea ice albedo feedback will 
ever be surmountable, and also whether extracting information about snow albedo feedback is possible at the present time.

To give an overview of the SAT and surface albedo variations in the scenario run, annualmean time series of these variables for $\mathrm{NH}$ and $\mathrm{SH}$ polar caps bounded by $30^{\circ}$ latitude are shown in fig 9. In both hemispheres, a steady warming trend becomes evident in the 20th century. This warming trend is very similar to that of the climate record: Over the course of the 20th century, the scenario run and the observed record both exhibit a global-mean warming of about $0.5^{\circ} \mathrm{C}$. In the scenario run, much greater warming occurs during the 21 st century. These warming trends result from steadily-increasing greenhouse gas and sulfate aerosol forcing and are superposed on significant internal SAT variability. The surface albedo time series also contains evidence of both externally-forced climate change and internal variability (figs $9 \mathrm{c}$ and d). In the $\mathrm{NH}$, a steady decrease in albedo begins early in the 20th century, with a larger downward trend in the 21st century. In the $\mathrm{SH}$, a downward trend in surface albedo also occurs, but it becomes visible toward the beginning of the 21 st century, much later than in the $\mathrm{NH}$. This trend is also delayed relative to the increase in SH SAT. The downward trends in surface albedo are obviously related to the increases in SAT, and a close examination of the early portion of the time series shown in fig 9 reveals that the internally-generated albedo fluctuations are also anti-correlated with the internally-generated surface temperature fluctuations. This is consistent with the negative regressions seen in fig 7 for the internal variability case.

\subsection{Measuring sea ice albedo feedback in the SH}

In section 5 it was demonstrated that in the $\mathrm{SH}$, SAF behaves very differently in the internal variability and $\mathrm{CO}_{2}$ doubling contexts. How then to extract information about SH SAF in the context of equilibrium climate sensitivity from a time series such as the scenario run or the observed 
record that contains both internal variability and a transient response to external forcing? It is clear from fig 9 that towards the beginning of the scenario run, the SAT and surface albedo variability in both hemispheres is mostly internally-generated, whereas by the end of the experiment most of the variations can be traced to external forcing. So is there a point in the scenario run when the signatures of external forcing become strong enough that they dominate the SH SAF statistics? If so, is the climate in close enough equilibrium with the external forcing that the SAF statistics resemble those of equilibrium climate change?

Addressing these questions allows an assessment of the practicality of extracting information about SAF's contribution to $\mathrm{SH}$ climate sensitivity from the observed record. This is done by examining the evolution of the regression of SH surface albedo onto SH SAT over the course of the scenario run (fig 10). This statistic changes in a similar way for all seasons. When the regression calculation is based on data from the beginning of the scenario run, it matches reasonably well the regression for pure internal variability measured in the VA internal variability experiment. This holds true as long as no scenario run data are used past about 1970. Internal climate variations therefore dominate the regression statistic well into the latter part of the 20th century despite the fact that the external forcing over the entire 20th century is significant. The signatures of external forcing take so long to emerge in the $\mathrm{SH}$ because of the slow response time scale of the SH climate system. This slow response time has been noted in numerous transient climate change experiments (e.g. Manabe et al., 1991, Dai et al. 2001), and is due to the deep convection in the Southern Ocean, which results in a large effective thermal inertia in this region.

As 100 year segments ending beyond 1970 are used, the regression rises slowly for all seasons. During JJA and SON, it reaches the value characteristic of equilibrium climate change when the regression calculation is based on data for 100 year segments ending beyond about 
2030. During DJF and MAM, it overshoots its $2 \mathrm{XCO}_{2}$ value, peaking for 100 year segments ending in the early to mid 21 st century. Then it slowly decreases so that when the calculation is based on a 100 year segment ending in 2094, the regression is reasonably close to the $2 \mathrm{XCO}_{2}$ value. The regression overshoots because much of the SH extratropical atmosphere during the early 21 st century has warmed somewhat in response to the external forcing. However, the Southern Ocean, being the component of the climate system with the most thermal inertia, still has not warmed much and the Southern Ocean's sea ice has decreased by a correspondingly small amount (see fig 9). When the small surface albedo change is regressed onto the relatively large SAT change, the result is a value closer to zero than the $2 \mathrm{XCO}_{2}$ value. Eventually the Southern Ocean equilibrates with the overlying atmosphere, sea ice retreats, and the albedoSAT statistics begin to resemble those of equilibrium sensitivity.

Based on this analysis of fig 10, it is likely impossible to estimate SH SAF by examining the observed climate record until well into the 21 st century because $\mathrm{SH}$ climate takes decades to respond to external forcing. The signatures of internal variability and the transient response to the external forcing contaminate the SAF statistics during some seasons until nearly the end of the 21st century.

\subsection{Measuring snow albedo feedback in the NH}

In section 5 it was demonstrated that in the $\mathrm{NH}$, the SAF due to snow on land behaves very similarly in the internal variability and $\mathrm{CO}_{2}$ doubling contexts. In this section, it is shown that this similarity, together with the high degree of thermodynamic equilibrium of $\mathrm{NH}$ continental climate with external forcing, can be exploited to extract information about equilibrium climate sensitivity from a time series such as the scenario run or the observed record that contains both internal variability and a transient response to external forcing. 
Fig 11 shows scatter plots of seasonal-mean surface albedo vs. seasonal mean SAT for $\mathrm{NH}$ snow-covered regions. During each season, the two variables are tightly correlated, falling on a fairly straight line. Moreover, the overall slope in each panel agrees nearly perfectly with the equilibrium relationship between surface albedo and SAT in the $\mathrm{CO}_{2}$-doubling context. This suggests the $\mathrm{NH}$ climate over snow-covered land areas in a high degree of thermodynamic equilibrium with the external forcing throughout the scenario run.

The surface albedo-SAT regression agrees with the $2 \mathrm{XCO}_{2}$ value regardless of the time period-and mix of internal variability and externally-forced variation-of the scenario run chosen. The cluster of points toward the upper left of each panel corresponds mostly to data from the first century and a half of the scenario run, when external forcing is weak and internal variations dominate the variability. The rest of the points derive principally from the rest of the experiment, when external forcing is large. The slopes of these two collections of points agree very well during every season, consistent with the fact that the simulated behavior of SAF in NH snow-covered land areas is the same in the internal variability and $\mathrm{CO}_{2}$-doubling contexts.

Even if snow albedo feedback behaved very differently in the internal variability and $\mathrm{CO}_{2}$ doubling contexts, external forcing in a region in thermodynamic equilibrium with it would dominate the statistics as soon as the externally-forced anomaly becomes larger than the internal variability. In the case of snow albedo feedback, however, the signatures of internal variability do little to contaminate the surface albedo-SAT relationship, so that it is not necessary to wait until the externally-forced anomaly becomes larger than internal variability. This raises the possibility that the present-day climate record may be adequate to achieve a statistically significant estimate of the real climate's SAF in the equilibrium climate sensitivity context. The satellite record of snow cover extends back to 1967, during which time a decrease in $\mathrm{NH}$ snow cover has been observed (Robinson, 1997; Robinson, 1999). Fig 12 demonstrates that this time series is likely 
more than long enough to measure the SAF in the climate sensitivity context, assuming it is possible to estimate both surface albedo and SAT using the satellite data. As more and more of the scenario run data going back in time from 2003 is used to calculate the regression between surface albedo and SAT over snow-covered areas, the regression converges reasonably well to the $2 \mathrm{XCO}_{2}$ value for all seasons once data from the early 1980 s is included.

\section{Summary and Implications}

A coarse resolution coupled ocean-atmosphere simulation where SAF is artificially suppressed by prescribing surface albedo is compared to one where snow and sea ice anomalies are allowed to affect surface albedo, as the model was originally designed. Canonical $\mathrm{CO}_{2}$-doubling experiments were performed with both models to assess the impact of SAF on equilibrium climate response to external forcing. There is about twice as much warming during all seasons in the $\mathrm{SH}$ in the zone of the sea ice margin when SAF is present. In the NH extratropics, the amplification is somewhat smaller in most seasons (about 60\%), probably because the simulated snow albedo feedback is somewhat weaker than sea ice albedo feedback. SAF also affects the warming far from regions where surface albedo changes in response to doubled $\mathrm{CO}_{2}$. For example, there is approximately $20 \%$ more warming in the tropics when SAF is present. Though SAF is the principal reason for overall polar amplification of the warming signal in both hemispheres, ice thickness feedback is the main determinant of the seasonal distribution of warming in the high latitudes.

Both models with and without SAF were also run for 1000 years without external forcing to assess the impact of SAF on internal variability and compare it to the feedback's impact on the response to $\mathrm{CO}_{2}$-doubling. SAF has a smaller amplifying effect on local internally-generated SAT anomalies than on the SAT increase due to a doubling of $\mathrm{CO}_{2}$. This occurs for two reasons: (1) 
Because local internally-generated SAT anomalies within the extratropics are only weakly correlated with one another, they are significantly damped by atmospheric motion. This horizontal damping dilutes the effect of radiative damping processes such as SAF. The SAT increase due to $\mathrm{CO}_{2}$ doubling, in contrast, is of the same sign everywhere, so that even the local $\mathrm{CO}_{2}$-induced increases in SAT are much less affected by horizontal damping than their internally-generated counterparts. (2) The SAF due to sea ice is enhanced in the $\mathrm{CO}_{2}$ doubling case by the ice thickness feedback, which does not come into play in the internal variability case because internallygenerated albedo variations are not associated with large enough changes in the ice thickness in the interior of the ice pack to significantly affect sensible heat flux through the ice.

SAF was also examined in the sensitivity and variability contexts in isolation from other processes affecting the damping of SAT by comparing the magnitudes of surface albedo anomalies associated with externally-forced and internally-generated SAT anomalies. Using this classical climate feedback framework, it was found that SAF due to sea ice behaves differently in the two contexts. In the $\mathrm{SH}$, systematically smaller changes in surface albedo occur on a per ${ }^{\circ} \mathrm{C}$ basis in the $\mathrm{CO}_{2}$-doubling case during all seasons. This is due to the ice thickness feedback, which increases the SAT anomaly associated with a given change in surface albedo stemming from a $\mathrm{CO}_{2}$-induced sea ice reduction. In the $\mathrm{NH}$, the surface albedo reduction due to loss of sea ice is significant during summer in the $\mathrm{CO}_{2}$ doubling case. However, internally-generated JJA SAT anomalies are not large enough to have significant sea ice albedo variations associated with them, so that the SAF due to sea ice also behaves differently in the internal variability and $\mathrm{CO}_{2}$ doubling contexts in the $\mathrm{NH}$.

In contrast to sea ice albedo feedback, $\mathrm{NH}$ snow albedo feedback behaves very similarly in the sensitivity and variability contexts. A given SAT anomaly in snow-covered regions produces roughly the same change in snow depth and surface albedo whether it is externally-forced or 
internally-generated. This suggests the presence of internal variability in the observed climate record is not a barrier to extracting information about snow albedo feedback's contribution to equilibrium climate sensitivity.

This is demonstrated in principle in the scenario run. The snow albedo feedback to the scenario run's climate anomalies agrees very well with the snow albedo feedback in the $\mathrm{CO}_{2}{ }^{-}$ doubling context, indicating the $\mathrm{NH}$ land areas are in high degree of thermodynamic equilibrium with the transient external forcing. The scenario run contains a mix of internal variations and externally-forced anomalies similar to the observed record. However, since snow albedo feedback behaves similarly in the sensitivity and variability contexts, the presence of internal variability does little to contaminate the SAF statistics. This reduces the number of years required to achieve a statistically stable estimate of snow albedo feedback in the sensitivity context. In fact, the portion of the scenario run corresponding to the present-day satellite record is long enough. This indicates the present-day satellite record could be used to estimate snow albedo feedback's contribution to equilibrium climate sensitivity. It is worth reiterating that variations in cloudiness in snow-covered regions associated with a changing climate-a factor not taken into account in the present study—could introduce uncertainty into an estimate of snow albedo feedback. This uncertainty would have to be assessed by examining observed and simulated cloud trends in snow-covered regions and evaluating how much they actually affect the influence of snow albedo on the top-of-the-atmosphere albedo.

Acknowledgments. This research was supported by NSF ATM-0135136 and a LamontDoherty Earth Observatory postdoctoral fellowship. The author wishes to thank the Geophysical Fluid Dynamics Laboratory in Princeton NJ for providing computational resources to carry out these experiments as well Amy Clement and two anonymous reviewers for very constructive 
criticism of this manuscript. 


\section{References}

Allison I., R.E. Brandt, S.G. Warren, 1993: East Antarctic sea ice: Albedo, thickness distribution, and snow cover. J. Geophys. Res., 98(C12), 12417-12429.

Barry, R.G., 1996: The parameterization of surface albedo for sea ice and its snow cover. Progr. Phys. Geogr., 20, 63-79.

Broccoli A.J.B., 2000: Tropical cooling at the last glacial maximum: an atmosphere-mixed layer ocean model simulation. J. Clim., 13, 951-976.

Bryan K., 1969: Climate and the ocean circulation: III. The ocean model. Mon. Wea. Rev., 97, 806-827.

Bryan K., L. Lewis, 1979: A water mass model of the world ocean. J. Geophys. Res., 84(C5), 2503-2517.

Budyko, M.I., 1969: The effect of solar radiation variations on the climate of the earth. Tellus, 21, 611-619.

Cubasch U. et al., 2001: Projections of future climate change. Climate Change 2001: The Scientific Basis. Contribution of Working Group I to the Third Assessment Report of the Intergovernmental Panel on Climate Change. Cambridge, UK: Cambridge University Press. $525-582$.

Dai A., T.M.L. Wigley, B.A. Boville, J.T. Kiehl, L.E. Buja, 2001: Climates of the 20th and 21st centuries simulated by the NCAR climate system model. J. Clim., 14, 485-519.

Cess R.D., G.L. Potter, 1988: A methodology for understanding and intercomparing atmospheric climate feedback processes in general circulation models. J. Geophys. Res., 93(D7), 8305-8314. 
Gordon C.T., W. Stern, 1982: A description of the GFDL Global Spectral Model, Mon. Wea. Rev., 110, 625-644.

Grenfell, T.C., D.K. Perovich, 1984: Spectral albedos of sea ice and incident solar irradiance in the southern Beaufort Sea, J. Geophys. Res., 89(C3), 18669-18684.

Hall A., S. Manabe, 1999: The role of water vapor feedback in unperturbed climate variability and global warming. J. Clim., 12, 2327-2346.

Hall A., S. Manabe, 2000a: Effect of water vapor feedback on internal and anthropogenic variations of the global hydrologic cycle. J. Geophys. Res., 105(D5), 6935-6944.

Hall A., S. Manabe, 2000b: Suppression of ENSO in a coupled model without water vapor feedback. Clim. Dyn. 16, 393-403.

Haywood J.M., R.J. Stouffer, R.T. Wetherald, S. Manabe, V. Ramaswamy, 1997: Transient response of a coupled model to estimated changes in greenhouse gas and sulfate concentrations. Geophys. Res. Lett., 24, 1335-1338.

Ingram W.J., C.A. Wilson, J.F.B. Mitchell, 1989: Modeling climate change: an assessment of sea ice and surface albedo feedbacks. J. Geophys. Res., 94(D6), 8609-8622.

IPCC (Intergovernmental Panel on Climate Change), 1992: Climate Change 1992: The supplementary report to the IPCC scientific assessment. Houghton JT, Varney SK (eds), Cambridge University Press, Cambridge UK.

Manabe S., 1969: Climate and the Ocean Circulation: I. The Atmospheric Circulation and the Hydrology of the Earth's Surface. Mon Wea Rev 97:739-774.

Manabe S., R.J. Stouffer, 1980: Sensitivity of a global climate model to an increase of $\mathrm{CO}_{2}$ concentration in the atmosphere. J. Geophys. Res., 85(C10), 5529-5554. 
Manabe S., R.J. Stouffer, M. Spelman, K. Bryan, 1991: Transient responses of a coupled oceanatmosphere model to gradual changes of atmospheric $\mathrm{CO}_{2}$. Part I: annual-mean response. J Clim 4, 785-817

Manabe S., R.T. Wetherald, 1975: The effects of doubling the $\mathrm{CO}_{2}$ concentration on the climate of a general circulation model. J. Atmos. Sci., 32, 3-15.

Marotzke J., P. Stone, 1995: Atmospheric transports, the thermohaline circulation, and flux adjustments in a simple coupled model. J. Phys. Oceanogr., 25, 1350-1364.

Massom R.A. et al., 2001: Snow on Antarctic sea ice. Rev. Geophys., 39, 413-445.

Mitchell J.F.B., T.C. Johns, J.M. Gregory, S.F.B. Tett, 1995: Climate response to increasing levels of greenhouse gases and sulfate aerosols, Nature, 376, 501-504.

Pacanowski R,, K. Dixon, A. Rosati, 1991: The G.F.D.L Modular Ocean Model Users Guide. GFDL Ocean Group Technical Report 2

Redi M.H. 1982: Oceanic isopycnal mixing by coordinate rotation. J. Phys. Oceanogr., 12, 1154-1158.

Robinson, D.A. 1997: Hemispheric snow cover and surface albedo for model validation. Ann. Glaciol., 25, 241-245.

Robinson, D.A., 1999: Northern hemisphere snow cover during satellite era. Proc. 5th Conf. Polar Met. and Ocean., Dallas, TX, American Meteorological Society, Boston, MA, pp 255260.

Robock A., 1980: The seasonal cycle of snow cover, sea ice, and surface albedo. Mon. Wea. Rev., 108, 267-285. 
Robock A., 1983: Ice and snow feedbacks and the latitudinal and seasonal distribution of climate sensitivity. J. Atmos. Sci., 40, 986-997.

Sellers, W.D., 1969: A global climatic model based on the energy balance of the earth-atmosphere system. J. Appl. Meteor., 8, 392-400.

Stouffer R., S. Manabe, K. Bryan, 1989: Interhemispheric asymmetry in climate response to a gradual increase of atmospheric carbon dioxide. Nature, 342, 660-662.

Stroeve J., A. Nolin, K. Steffen, 1997: Comparison of AVHRR-derived and in situ surface albedo over the Greenland ice sheet. Remote. Sens. Environ., 62, 262-276.

Tziperman E., K. Bryan, 1993: Estimating global air-sea fluxes from surface properties and from climatological flux data using an oceanic general circulation model. J. Geophys. Res., 98(C12), 22629-22644.

Wiscombe, W.J., Warren, S.G., 1980: A Model for the Spectral Albedo of Snow. I: Pure Snow. J. Atmos. Sci., 37, 2712-2733. 

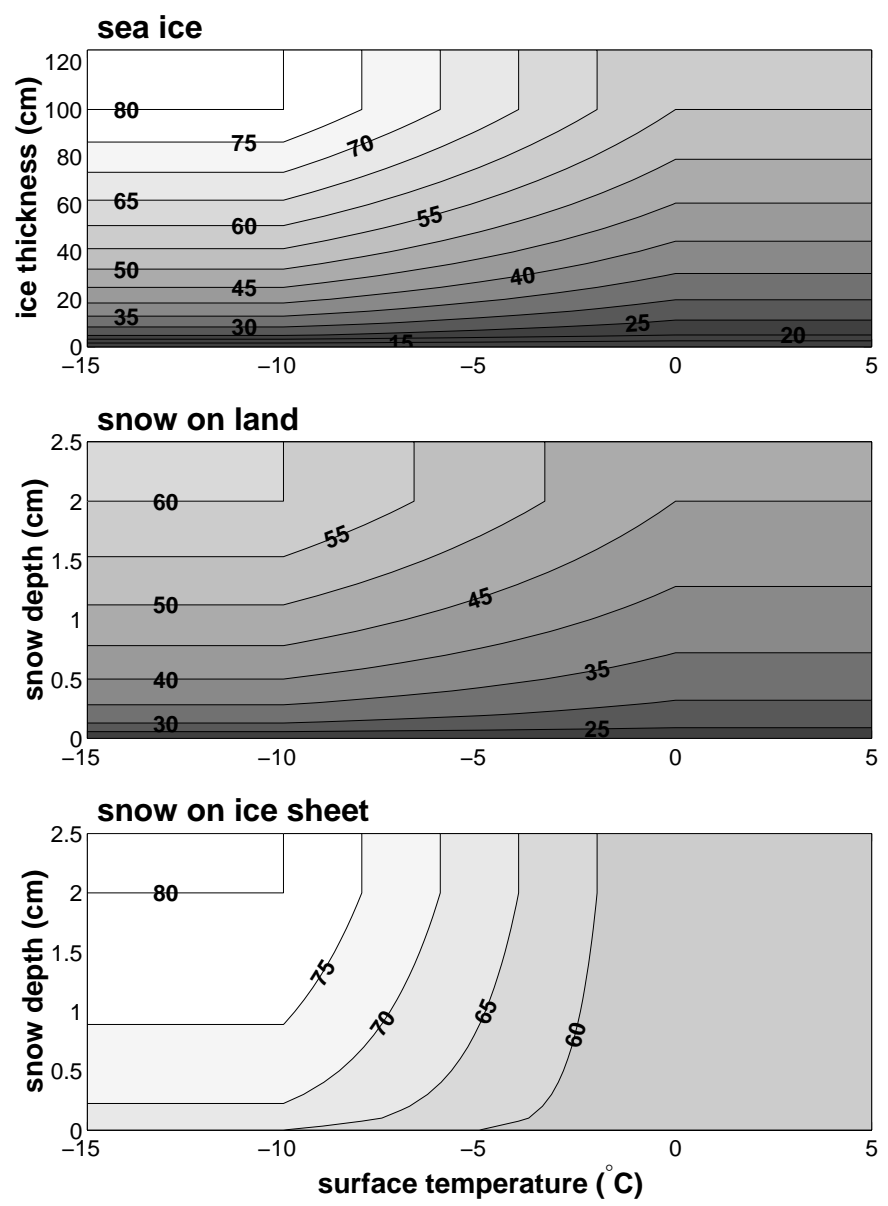

Figure 1: The model's surface albedo parameterization: Variation of surface albedo (\%) with ice thickness and surface temperature for a typical high-latitude ocean location (top), waterequivalent snow depth and surface temperature for a typical mid-latitude land location (middle), and water-equivalent snow depth and surface temperature for land regions covered by ice sheets (bottom). 

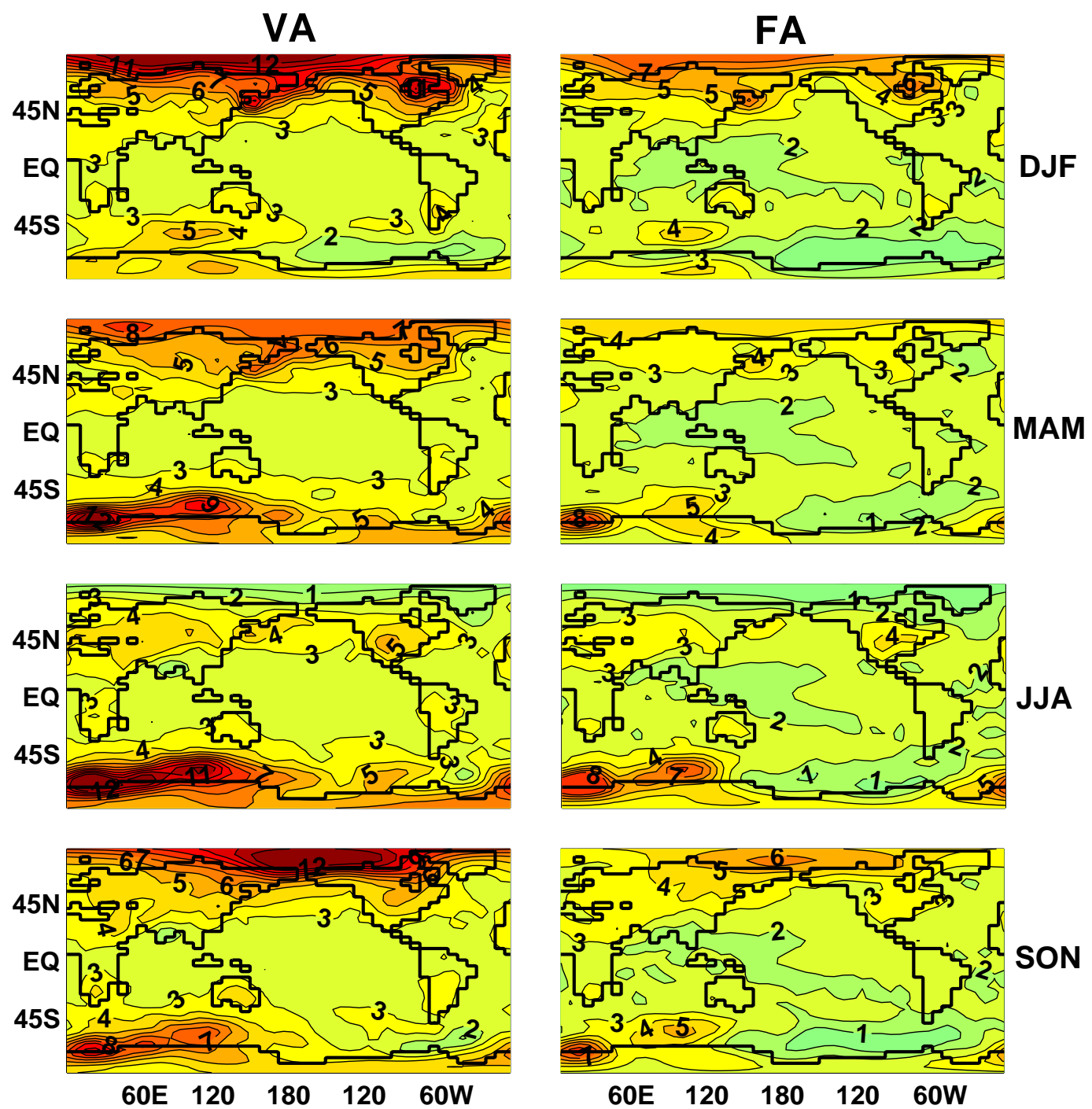

Figure 2: Left column: the geographical distribution of the quasi-equilibrium SAT $\left({ }^{\circ} \mathrm{C}\right)$ increase occurring as a result of $\mathrm{CO}_{2}$ doubling in the VA experiment. As noted in section 3, the climate variables averaged over the fifth century of the $\mathrm{CO}_{2}$-doubling experiments were compared to the climate variables averaged over the fifth century of the internal variability experiments to assess the quasi-equilibrium response to doubled $\mathrm{CO}_{2}$. Results from all four seasons are shown. Right column: As in the left column, except for the FA model. 


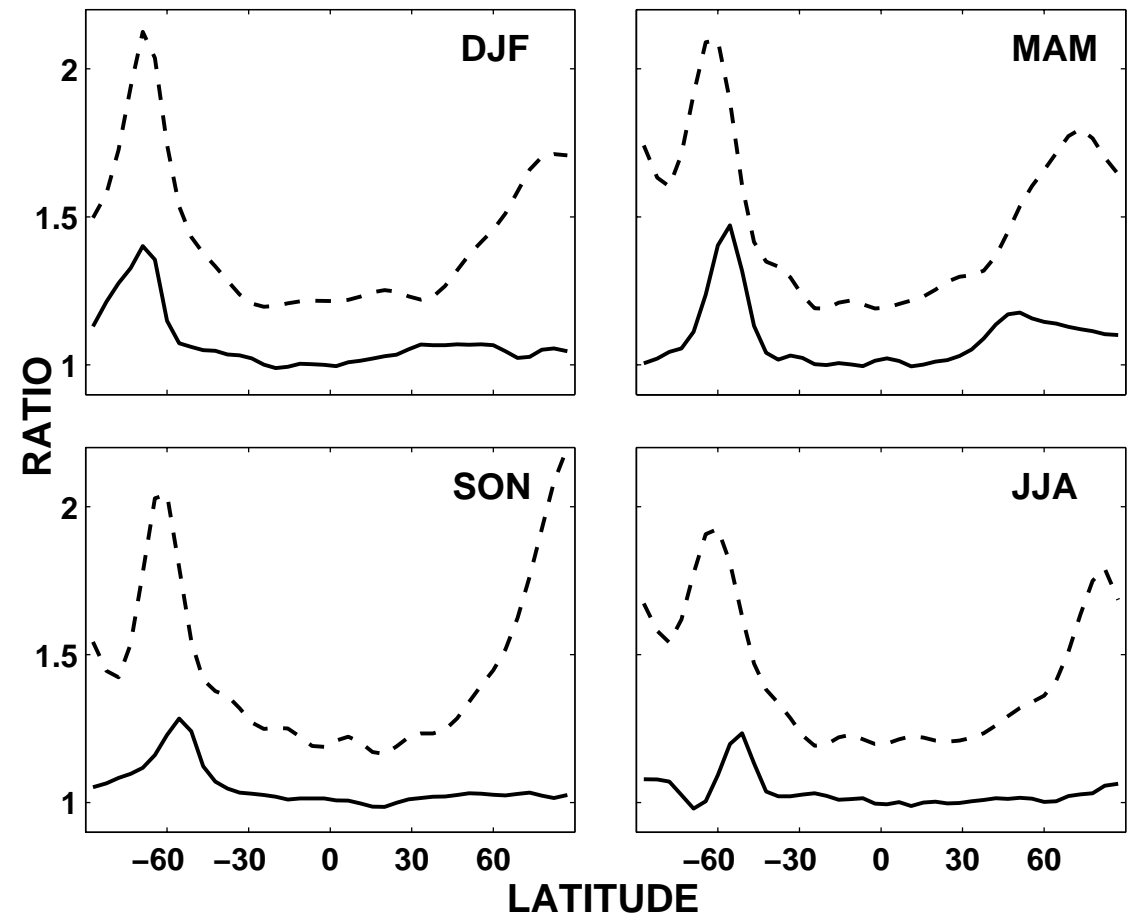

Figure 3: Dashed lines: The ratio (VA/FA) of the zonal-mean quasi-equilibrium SAT increase resulting from a doubling of $\mathrm{CO}_{2}$ for all four seasons. Solid lines: The ratio (VA/FA) of the zonal-mean standard deviation of seasonal-mean SAT at each grid point in the internal variability experiments for all four seaons. 


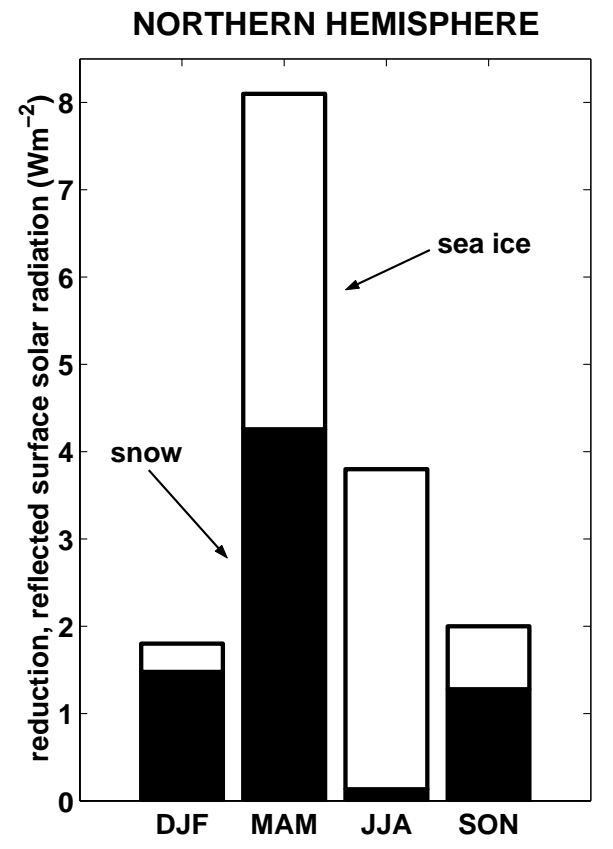

\section{SOUTHERN HEMISPHERE}

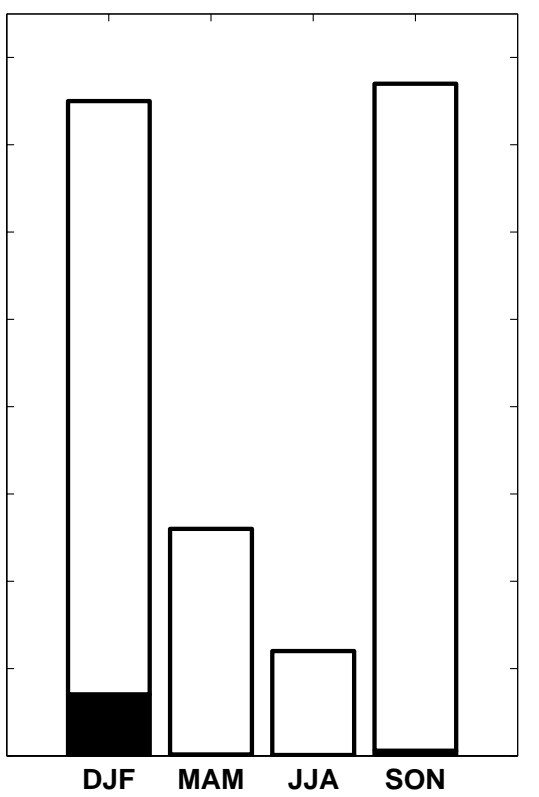

Figure 4: Seasonal breakdown in the VA model of the quasi-equilibrium reduction in solar radiation $\left(\mathrm{Wm}^{-2}\right)$ at the surface due to $\mathrm{CO}_{2}$ doubling averaged over polar caps bounded at $30^{\circ} \mathrm{N}$ and $\mathrm{S}$. The left panel is for the $\mathrm{NH}$ polar cap, while the right panel is for its $\mathrm{SH}$ counterpart. The black bars denote the contribution to the total reduction from snow on land, while the white bars denote the contribution from sea ice. The reduction in reflected solar radiation at the surface is estimated by multiplying the surface albedo change due to $\mathrm{CO}_{2}$ doubling by the climatological downward shortwave radiation in the unperturbed VA model at each grid point. This plot therefore represents the change in net incoming radiation at the surface assuming no change in the overlying atmosphere, including its cloud distribution. 


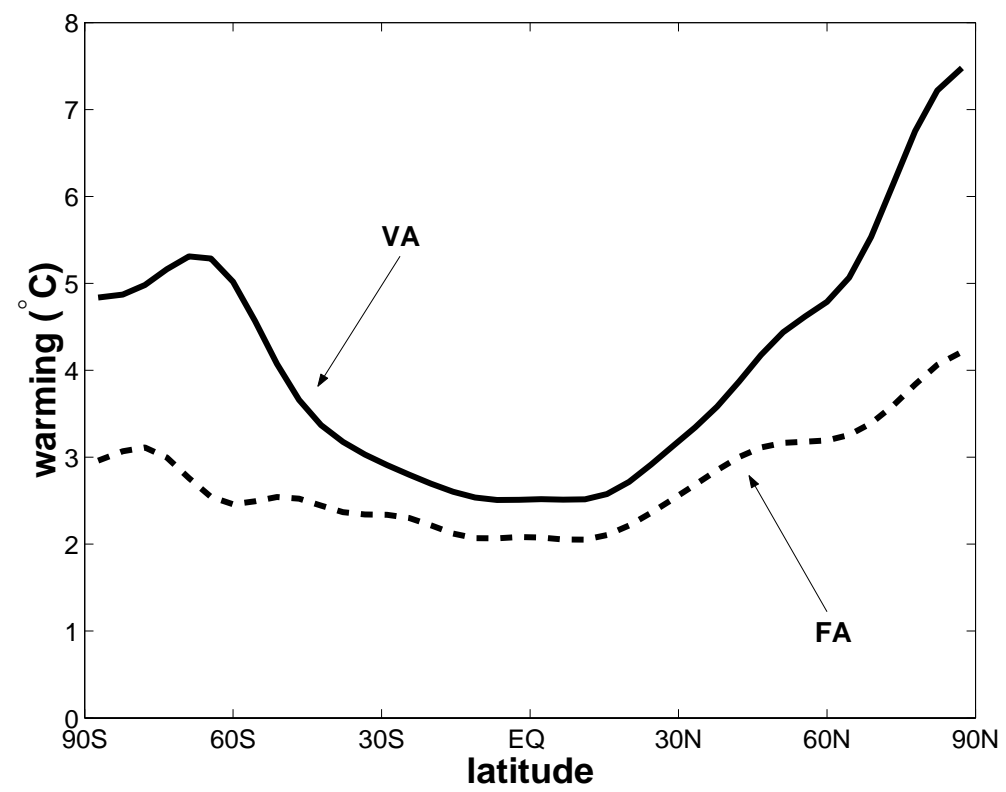

Figure 5: The quasi-equilibrium zonal-mean, annual-mean warming resulting from $\mathrm{CO}_{2}$ doubling in the FA (dashed line) and VA (solid line) models. 

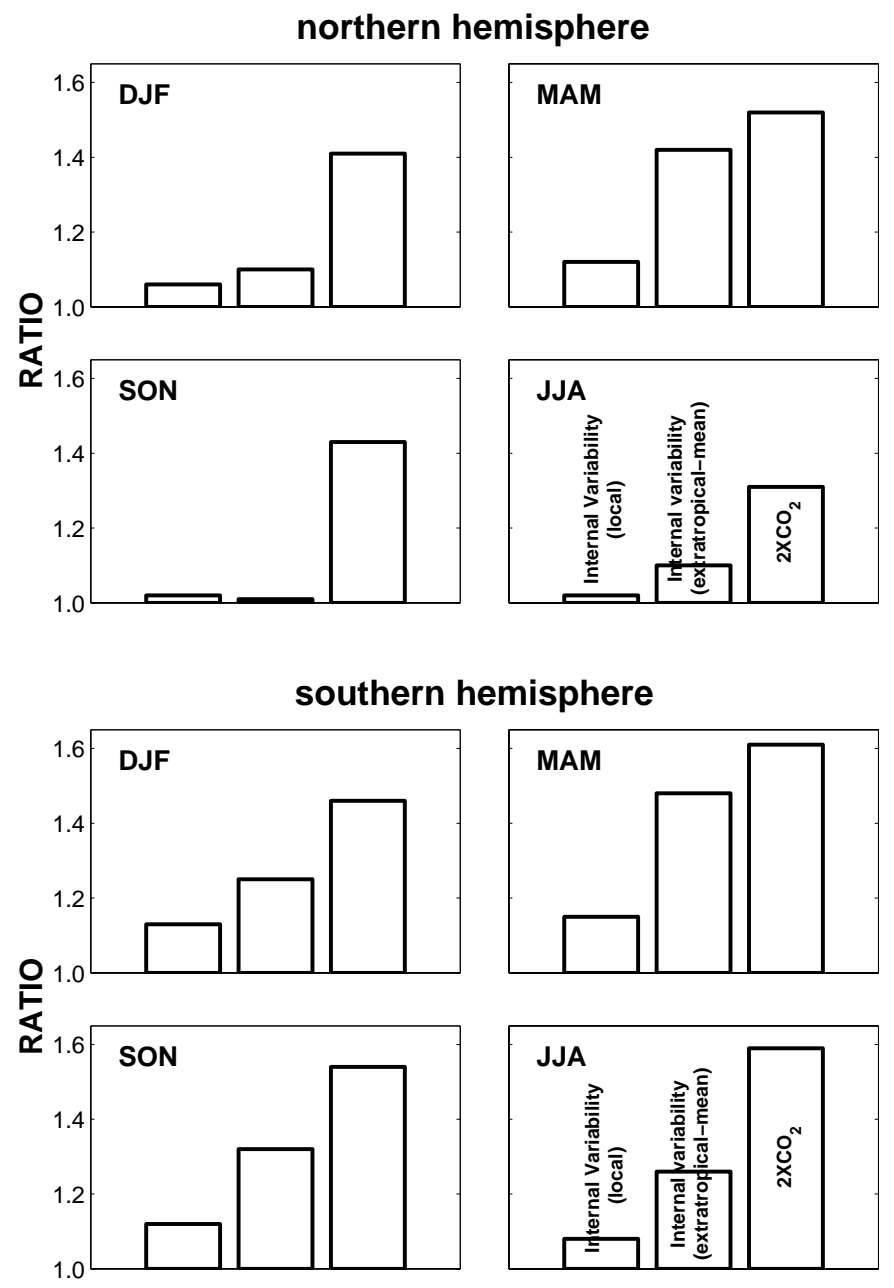

Figure 6: Comparison between the VA and FA models of the magnitudes of internally-generated and externally-forced seasonal-mean SAT anomalies in the $\mathrm{NH}$ and $\mathrm{SH}$ extratropics. The extratropics are defined as the regions poleward of $30^{\circ} \mathrm{N}$ and $30^{\circ} \mathrm{S}$. In each panel, the left bar is the VA/FA ratio of seasonal-mean SAT standard deviation in the internal variability experiments, calculated first at every model grid point and then averaged over the extratropics (i.e. the ratios shown in fig 3 averaged over the extratropics). The middle bar of each panel is the VA/FA ratio of the standard deviation of extratropical-mean, seasonal-mean SAT variations in the internal variability experiments. The right bar of each panel is the quasi-equilibrium seasonal-mean SAT warming averaged over the extratropics in the $2 \mathrm{XCO}_{2} \mathrm{VA}$ experiment divided by that of the $2 \mathrm{XCO}_{2}$ FA experiment. The top (bottom) four panels are for the $\mathrm{NH}(\mathrm{SH})$ extratropics. 


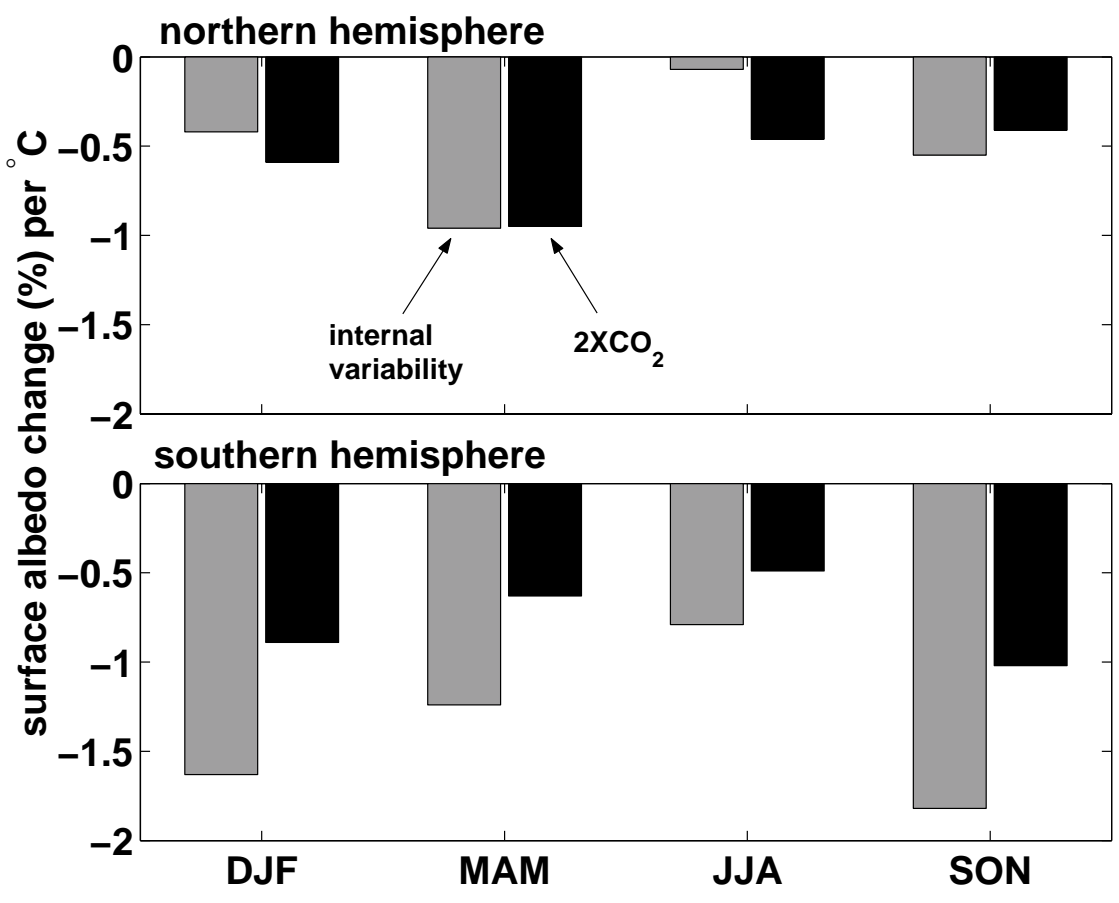

Figure 7: Seasonal breakdown of the relationship in the extratropics between surface albedo and SAT in the contexts of internal variability and $\mathrm{CO}_{2}$ doubling (VA model). For the internal variability case (grey bars), the values shown are regressions of seasonal-mean surface albedo onto SAT, where both variables are first averaged over $\mathrm{NH}$ and $\mathrm{SH}$ polar caps bounded by $30^{\circ}$ latitude. For the $\mathrm{CO}_{2}$-doubling case (black bars), the values shown are the quasi-equilibrium seasonal-mean changes in surface albedo due to $\mathrm{CO}_{2}$-doubling averaged over $\mathrm{NH}$ and $\mathrm{SH}$ polar caps bounded by $30^{\circ}$ latitude divided by the $\mathrm{CO}_{2}$-induced changes in SAT averaged over the same regions. The top panel shows the results for the $\mathrm{NH}$, while the bottom panel shows the results for the $\mathrm{SH}$. In this calculation and all subsequent calculations involving surface albedo (i.e. figs 8, 9, 10, 11, and 12), surface albedo values are weighted by the climatological incoming solar radiation at the surface in the unperturbed VA experiment prior to averaging. 

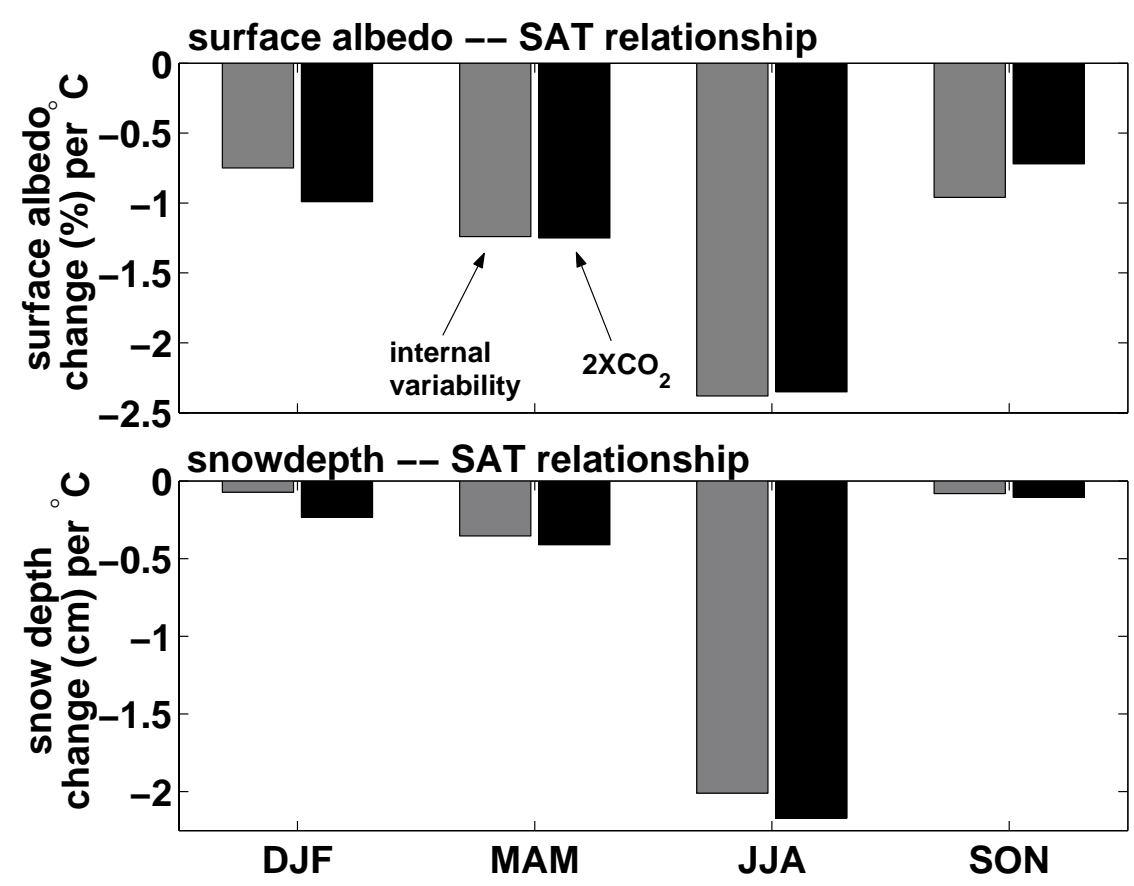

Figure 8: Top: Seasonal breakdown of the relationship between surface albedo and SAT in NH snow-covered regions for internal variability and $\mathrm{CO}_{2}$-doubling contexts. The grey bars show the regression of seasonal-mean surface albedo onto SAT in the VA internal variability experiment, where both variables are first averaged over $\mathrm{NH}$ snow-covered regions. The black bars show the quasi-equilibrium seasonal-mean changes in surface albedo due to $\mathrm{CO}_{2}$-doubling averaged over $\mathrm{NH}$ snow-covered regions divided by the $\mathrm{CO}_{2}$-induced changes in SAT averaged over $\mathrm{NH}$ snow-covered regions (VA model). Bottom: As in top panel, except for the relationship between snow depth and SAT averaged over snow-covered regions of the $\mathrm{NH}$. Snow-covered regions of the $\mathrm{NH}$ are defined as grid points in the VA internal variability experiment that had at least some snow at some point during the 1000-year long run, and are similarly defined for the calculations shown in figs 11 and 12 . 

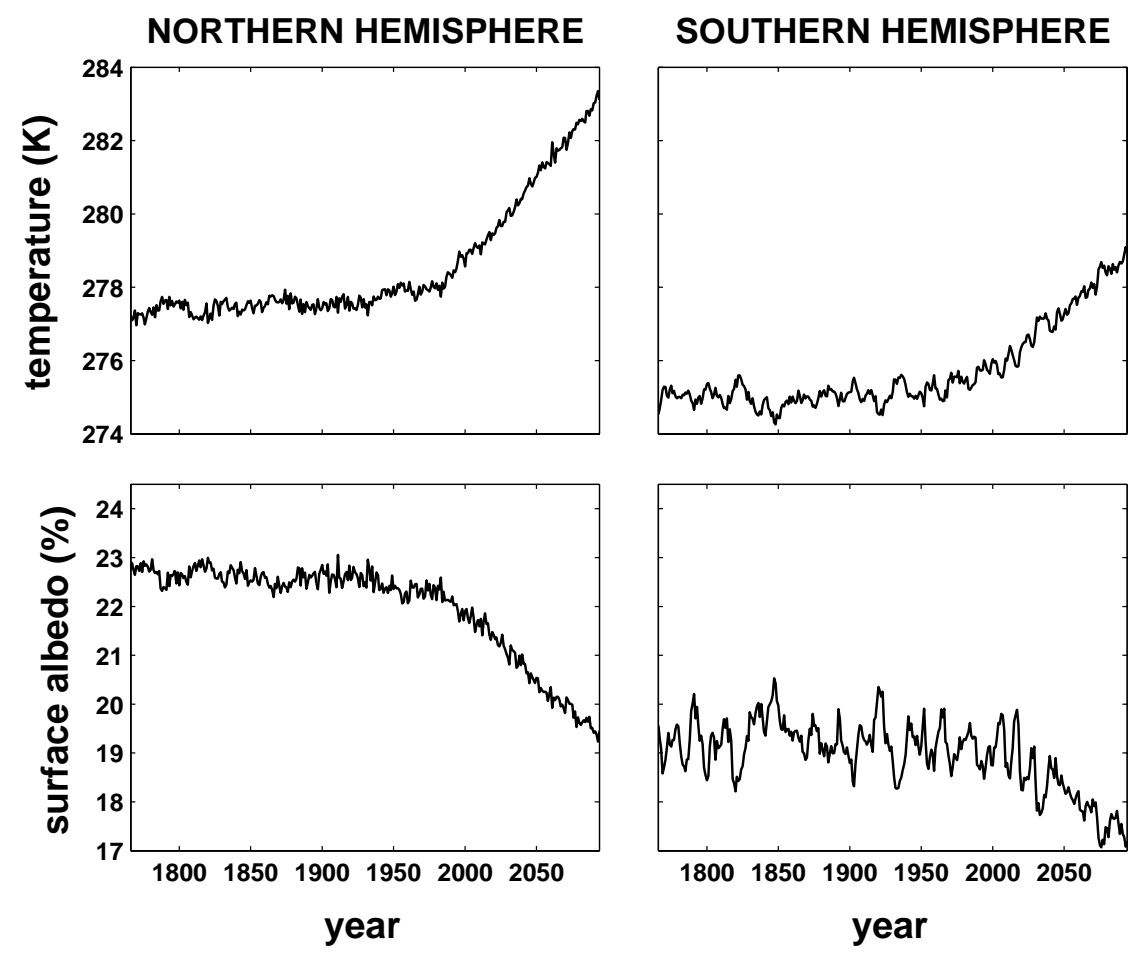

Figure 9: Annual-mean time series from the scenario run of SAT and surface albedo averaged over $\mathrm{NH}$ and $\mathrm{SH}$ polar caps bounded by $30^{\circ}$ latitude. 


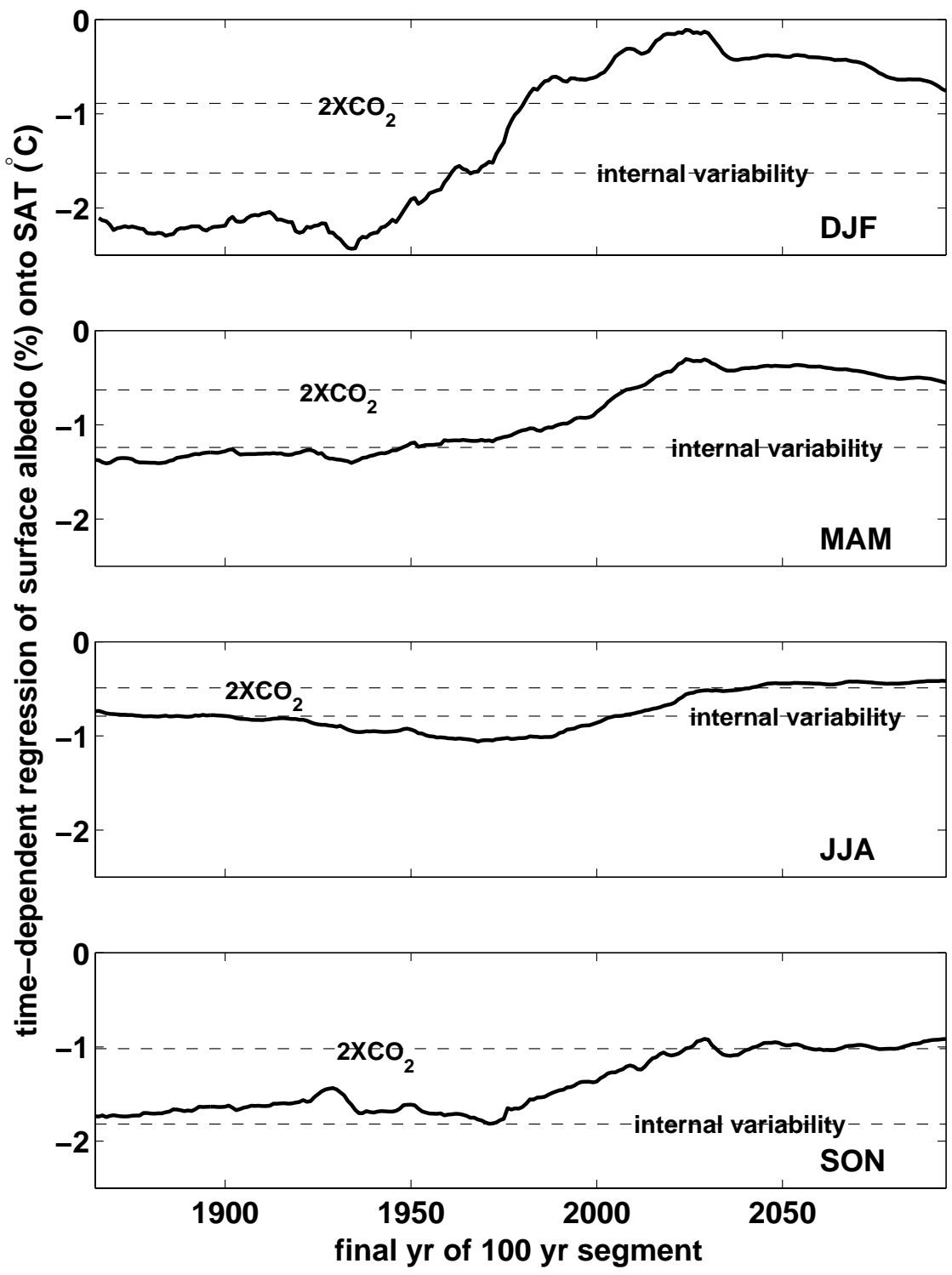

Figure 10: The time-dependent regression of seasonal-mean surface albedo averaged over a SH polar cap bounded by $30^{\circ} \mathrm{S}$ onto seasonal-mean SAT averaged over the same region in the scenario run. Regressions were calculated using all possible 100 year segments of the 330-yearlong run. The regressions were then plotted against the ending year of the 100-year segment used to calculate them, so that the value corresponding to 1900 on the plot is the regression of surface albedo onto SAT for the years 1801-1900. Results for all four seasons are shown. In addition, the relationships between surface albedo and SAT for the pure internal variability and $\mathrm{CO}_{2}$-doubling cases shown in the bottom panel of fig 7 are illustrated with dashed lines. 


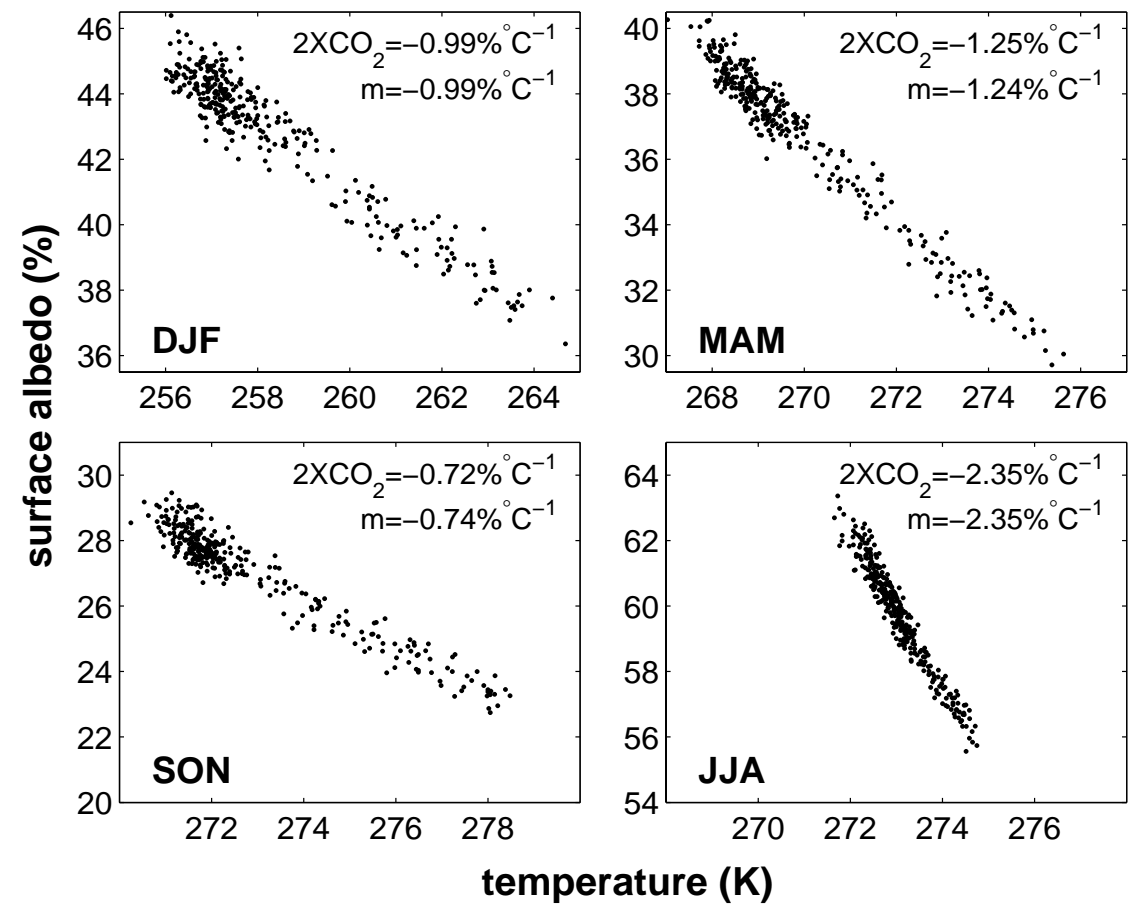

Figure 11: Scatter plots of seasonal-mean surface albedo vs. SAT averaged over snow-covered regions of the $\mathrm{NH}$ from the scenario run. The regression coefficient, $\mathrm{m}$, between the two variables is noted for each season. Also noted (as $\left.2 \mathrm{XCO}_{2}\right)$ are the quasi-equilibrium seasonal-mean changes in surface albedo due to $\mathrm{CO}_{2}$-doubling divided by the $\mathrm{CO}_{2}$-induced changes in SAT averaged over $\mathrm{NH}$ snow-covered regions (i.e. values associated with the black bars of the top panel of fig 8). NH snow-covered regions are defined in the same way as fig 8 . The span of the $x$ and $y$ axes is the same for all four panels. 


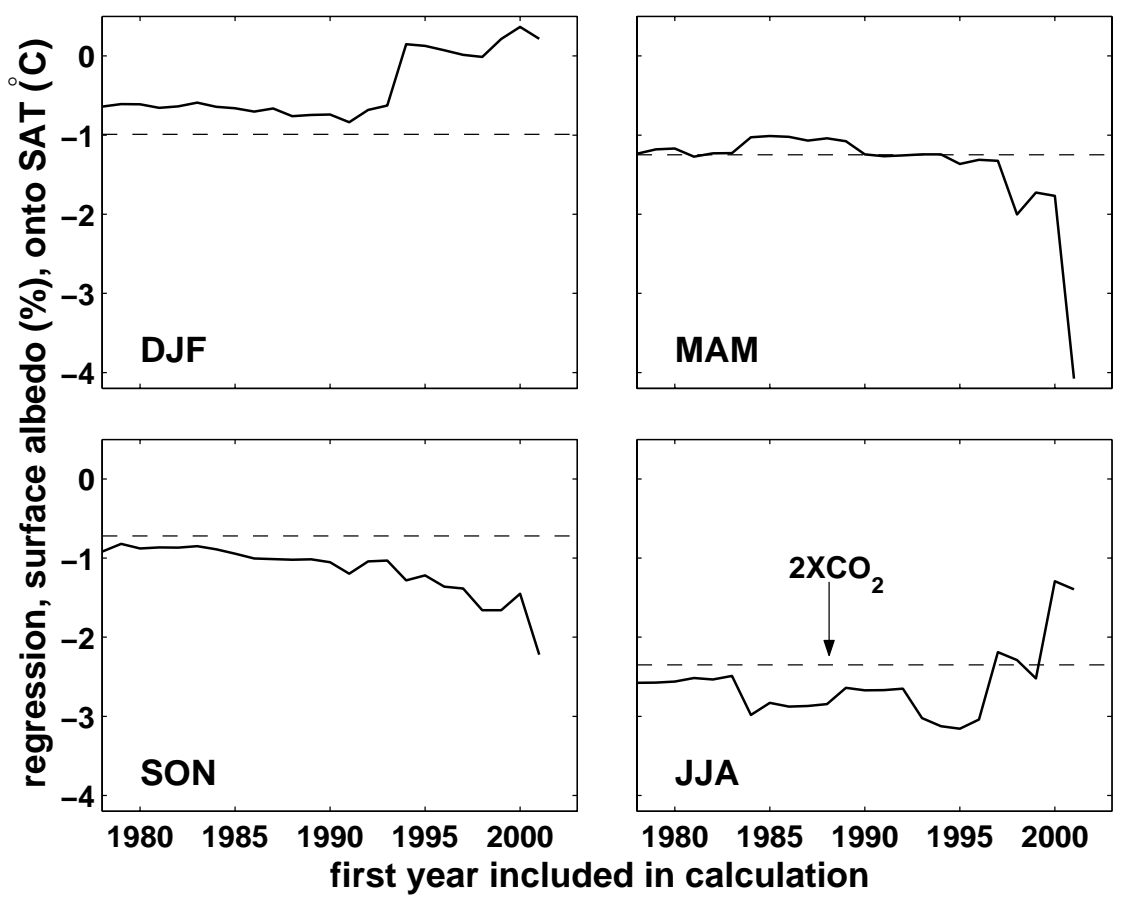

Figure 12: Regression coefficient of seasonal-mean surface albedo against SAT averaged over $\mathrm{NH}$ snow-covered regions as a function of the years from the scenario run simulation included in the regression calculation. The time periods used in the regression calculations all end in the year 2003. The abscissa of all panels represents the beginning year of the time periods used in the regression calculations. For example, the regression coefficient plotted for year 1980 is calculated using data from the years $1980-2003$. Also shown as dashed lines are the quasi-equilibrium seasonal-mean changes in surface albedo due to $\mathrm{CO}_{2}$-doubling divided by the $\mathrm{CO}_{2}$-induced changes in SAT in snow-covered areas of the $\mathrm{NH}$ (i.e. values associated with the black bars of the top panel of fig 8). NH snow-covered regions are also defined in the same way as fig 8. 